Forum Review Article

\title{
Concentration does matter: The beneficial and potentially harmful effects of ascorbate in humans and plants
}

\author{
Szilvia Z. Tóth ${ }^{1^{*}}$, Tamás Lőrincz ${ }^{2}$, András Szarka ${ }^{2 *}$ \\ ${ }^{1}$ Institute of Plant Biology, Biological Research Centre of the Hungarian Academy of \\ Sciences, Szeged, Temesvári krt. 62, H-6726 Szeged, Hungary \\ ${ }^{2}$ Department of Applied Biotechnology and Food Science, Laboratory of Biochemistry and \\ Molecular Biology, Budapest University of Technology and Economics, Szent Gellért tér 4. \\ H-1111 Budapest, Hungary \\ Running head: The roles of ascorbate in humans and plants \\ *Corresponding authors: \\ Dr. Szilvia Z. Tóth \\ Tel: +36 62599 733, e-mail address: toth.szilviazita@brc.mta.hu \\ Dr. András Szarka \\ Tel.: +36 1 4633858, e-mail: szarka@mail.bme.hu
}

Words: 7943

References: 176

Greyscale illustrations: 3

Color illustrations: 3 (online 3 and hardcopy 0)

Keywords: ascorbate, ascorbate biosynthesis, cell death, pharmacologic ascorbate, photosynthesis, reactive oxygen species 


\section{Introduction}

Ascorbate is one of the most widely known vitamins, which has a range of essential functions both in animals and plants. Because of its hydrophilic nature, it is highly soluble in water $(0.33 \mathrm{~g} / \mathrm{mL})$, less soluble in ethanol $(0.02 \mathrm{~g} / \mathrm{mL})$, and insoluble in oils, fats and fat solvents. Consequently it needs various transport proteins to pass through biological membranes (104). This characteristic feature also provides the possibility to set different ascorbate concentrations in different cell types and cell organelles $(11,104)$.

The donation of one electron to a redox partner results in the formation of monodehydroascorbate (MDA) (Fig. 1), which is also called ascorbyl radical. Upon further oxidation of the radical, dehydroascorbate (DHA) is formed (Fig. 1). Several metals, such as copper and iron, catalyse the oxidation of Asc. DHA then undergoes irreversible hydrolysis to 2,3-diketo-L-gulonic acid which may be further oxidized to oxalic acid and L-threonic acid (Fig. 1, see also below). The poor reactivity of ascorbyl radical makes Asc an excellent scavenger of reactive oxygen species (ROS), thereby it protects various cellular functions particularly under stress conditions. On the other hand, Asc is also a cofactor of several enzymes participating in a range of physiological processes and it also has other, recently discovered roles both in animals and plants.

Ascorbate is most often regarded as a protective agent and there has been considerable effort to increase its concentration in fruits and vegetables, with the goal of both increasing stress tolerance of plants and to generate high-value agricultural products. However, these efforts have been accompanied with moderate success, possibly due to the strong feedback regulation of Asc on its own biosynthesis in plants. Furthermore, Asc at high concentration has been shown to behave as a prooxidant in isolated thylakoid membranes (163), just as well as in human cells (127). As reviewed here, the cellular Asc level in plants and humans seem to be regulated by various mechanism, including its degradation and cellular transport, suggesting that maintaining its concentration in a certain range is of high physiological importance. This becomes evident when considering that Asc is a reducing agent and also has a regulatory role in various cellular functions. On the other hand, its prooxidant property has the potential to be applied in cancer therapy. 
2. The physiological roles of Asc in humans and plants: more than just an antioxidant

\subsection{The roles of Asc in humans}

Our knowledge on the biological functions of vitamin C is continuously expanding (Fig. 2A). All these known functions are based on its characteristic feature to be an excellent electron donor, i.e. reductant. By this means, Asc efficiently scavenges reactive oxygen (ROS) and nitrogen (RNS) species, which are by-products of oxidative metabolism and formed under various stress situations, that may lead to cellular damage (11). Asc also acts as a reducing cofactor for many enzymes, including copper-containing monooxygenases (22) and Fe(II)/2-oxoglutarate-dependent dioxygenases (97). These enzymatic reactions make Asc to be indispensable for the synthesis of carnitine (73) and catecholamines (9), and for the posttranslational modification of extracellular matrix proteins, including collagen (152). Asc may also be involved in another posttranslational modification, in the formation of disulphide bridges (152). It was recently discovered that 2-oxoglutaratedependent dioxygenases are also epigenetic erasers by hydroxylating methyl-lysine residues in histones (Jumonji-C domain-containing histone demethylases) and 5-methylcytosine in ten-eleven translocases (TETs) (86). Iron-containing 2-oxoglutarate-dependent enzymes also downregulate HIF-1 (85). As Asc is a specific cofactor for these enzymes, it definitely affects their activities. Asc is also a modulator of cellular iron metabolism. Beyond the known ability of dietary Asc to enhance non-heme iron absorption in the gut, accumulating evidence suggests that Asc can also regulate cellular iron uptake and downstream cellular metabolism (Fig. 2A) (89).

\subsection{The roles of Asc in plants}

In plants, the best-known function of Asc is to prevent the over-accumulation of ROS, which are formed during photosynthetic reactions occurring in the chloroplast, as a byproduct of respiration in the mitochondria (reviewed by (72)) and ROS are also generated 
in the peroxisomes, due to their oxidative type of metabolism (reviewed by (41)). As a nonenzymatic antioxidant, Asc is able to detoxify singlet oxygen $\left({ }^{1} \mathrm{O}_{2}{ }^{-}\right)$and hydroxyl radical $\left(\mathrm{OH}^{\circ}\right)$. Asc can also scavenge lipid peroxyl radicals and thereby participate in the recycling of tocopheroxyl radicals to tocopherol in plants (Fig. 2B) (reviewed by (118)).

Asc plays an essential role in the highly-regulated enzymatic scavenging of ROS in the socalled Mehler reaction or water-water cycle as well. In the Mehler reaction superoxide $\left(\mathrm{O}_{2}{ }^{--}\right)$is produced at the acceptor side of photosystem I (PSI), via the reduction of $\mathrm{O}_{2}$ by ferredoxin. It is then reduced to $\mathrm{H}_{2} \mathrm{O}_{2}$ by superoxide dismutase (SOD), and Asc peroxidase (APX) reduces $\mathrm{H}_{2} \mathrm{O}_{2}$ to water. MDA can be directly reduced back to Asc by PSI, and/or in the Asc-glutathione cycle. Monodehydroascorbate reductase (MDAR) and dehydroascorbate reductase (DHAR) use NADPH as reducing power to regenerate Asc (for details of this reaction, see $(5,55)$; $(37)$ for microalgae).

Besides its role in controlling the amount of ROS, Asc participates in a large number of enzymatic reactions in the plant cell. It serves as a cofactor of violaxanthin-deepoxidase (VDE), the enzyme responsible for the conversion of violaxanthin to zeaxanthin upon illumination leading to thylakoid lumen acidification (e.g. (67)). Zeaxanthin accumulation results in the increase of excess excitation energy dissipation as heat (e.g. $(68,122))$ and zeaxanthin is also an efficient scavenger of $\operatorname{ROS}(42,43)$. The role of Asc in the thermal dissipation of the excess excitation energy is well-documented in seed plants, although it is unknown whether Asc is a cofactor of algal-type VDE as well (94).

In plants, Asc functions as a cofactor for prolyl hydroxylases (125, 174); 1 aminocyclopropane-1-carboxylate oxidase that catalyzes the last reaction of ethylene biosynthesis $(14,145)$. Asc is also a substrate for 2-oxoacid-dependent dioxygenases, which are involved in the synthesis of abscisic acid, gibberellins $(99,128)$, and Asc also influences ethylene (110) and salicylic acid biosynthesis (13) and anthocyanin accumulation upon high-light exposure (126).

By being involved in abscisic acid signaling $(99,128)$, Asc also plays a role in the regulation of stomatal movement $(52,144)$. Asc also regulates embryo development (e.g. (32)), cell elongation and progression through the cell cycle, via poorly understood mechanisms 
(reviewed by (59)). It is conceivable that Asc plays a role in the cell cycle via its recently discovered role in epigenetic regulation (24), a possibility that has not been investigated in plants yet.

Thanks to its reducing properties, Asc is also an alternative electron donor to photosystem II (PSII) in higher plants and green algae under conditions where the oxygen-evolving complex (OEC) is impaired, for instance, upon heat stress $(157,158)$. The process of electron donation from Asc to $\mathrm{Tyr}_{z}^{+}$is physiologically relevant as it slows down the inactivation of PSII reaction centers and allows a faster recovery from heat stress. Asc has also been shown to provide electrons to PSII and PSI in bundle sheath cells of NADP-malic enzyme-type species of C4 plants, which are deficient in oxygen evolution. The physiological role of this process, most likely, is to poise PSI cyclic electron transport, responsible for the generation of ATP in bundle sheath cells (76).

The above-mentioned functions demonstrate that Asc is a major player in cellular physiology (Fig. 2B), thus much more than just an antioxidant, as pointed out earlier by (4). We also note that the antioxidant properties of Asc have been described in detail, but its roles in enzymatic reactions certainly warrant further investigations.

\section{The regulation of cellular ascorbate levels}

\subsection{The regulation of ascorbate concentration in human tissues and cells}

Due to a large number of mutations in the gene of L-gulono-gamma-lactone oxidase, the ultimate enzyme of Asc biosynthesis (121), humans have lost the ability to synthesize Asc; therefore, they need to obtain Asc from their diets. The level of Asc in tissues and cells is determined by its absorption (intestinal and (sub)cellular transport) and reabsorption (in kidneys).

The major natural dietary sources of vitamin $C$ are fruits and vegetables. These plant sources contain both the reduced form Asc and the oxidized form DHA, although the 
concentration of Asc largely exceeds that of DHA (53). Asc may get oxidized within the lumen of the gastrointestinal tract (87). It is also worth to note that DHA, similarly to Asc can prevent scurvy (155), because it can be reduced to Asc by glutathione or in NADPHdependent reactions (18). Both major forms of vitamin C, Asc and DHA are absorbed along the entire length of the human intestine, as it was shown by the investigation of the transport activity of luminal (brush border) membrane vesicles (103). The transport of both forms showed saturation with an apparent $\mathrm{K}_{\mathrm{M}}$ of $267 \pm 33 \mu \mathrm{mol} / \mathrm{L}$ for Asc and $805 \pm$ $108 \mu \mathrm{mol} / \mathrm{L}$ for DHA (103). The transport of Asc was proved to be $\mathrm{Na}^{+}$-dependent while the uptake of DHA was $\mathrm{Na}^{+}$-independent. Asc crosses the apical membrane with $2 \mathrm{Na}^{+}$ions, whereas DHA enters through facilitated diffusion. Asc uptake is inhibited by the increasing intracellular concentration of glucose (trans inhibition). The external (cis side) glucose does not interfere with Asc uptake and the observation that $\mathrm{SCN}^{-}$inhibits Asc uptake while stimulates the glucose transport clearly rule out the mediation of Asc transport by the $\mathrm{Na}^{+}-$ dependent glucose transporter SGLT1. The uptake of DHA was not influenced by glucose (103). The relatively low affinity of DHA transport compared with Asc transport indicates that most vitamin $\mathrm{C}$ is absorbed in the form of Asc.

The colon carcinoma cell line CaCo-2 is widely used as an in vitro model for enterocyte-like cells. The kinetics, the inhibition profile, the $\mathrm{Na}^{+}$dependence of transport and reverse transcriptase-PCR analysis indicate that the $\mathrm{Na}^{+}$-Asc co-transporters SVCT1 and SVCT2, the DHA transporters GLUT1 and GLUT3, and a third DHA transporter with characteristics of GLUT2 are expressed in CaCo-2 cells. It is in agreement with the observations that DHA is taken up by different members of the facilitative glucose transporter family (Fig. 3) (SLC2). GLUT1, 2, 3 and 4 from class I and GLUT8, 10 from class III glucose transporters are considered as efficient DHA transporters $(37,92,136,135,166)$. Since vitamin C can be detected in the human plasma practically only in its reduced form (43), the transport of DHA may be negligible under normal conditions. Directed localization of SVCT1 in the apical membrane of CaCo-2 cell monolayers was found (108). The apical cell surface expression of SVCT1 was also reinforced in renal and intestinal cells by (147). Later the accumulation of SVCT2 at the basolateral surface was described. This differential epithelial membrane localization suggests non-redundant functions of the two SVCTs (17). A 
basolateral targeting sequence in the N-terminus of SVCT2 is crucial for directing the protein to the basolateral membrane. Without this targeting sequence SVCT2 was redirected to the apical side (165).

SVCT1 represents a high-capacity Asc transporter with lower affinity ( $\left.\mathrm{K}_{\mathrm{M}}: 29-237 \mu \mathrm{M}\right)$. It mostly occurs in epithelial tissues such as intestine, lung, liver, kidney, and skin, where it is involved in the absorption and (renal) reabsorption of Asc to maintain the whole-body homeostasis $(106,161,171)$. Knockout of the SVCT1 transporter gene resulted in 7- to 10fold higher urinary loss and $50-70 \%$ lower blood level of vitamin C in mice compared to wild-type littermates (33).

SVCT2 can be characterized by lower capacity and higher affinity ( $\mathrm{K}_{\mathrm{M}}$ : 8-115 $\left.\mu \mathrm{M}\right)$ than SVCT1. It is widely expressed in tissues such as brain, lung, liver, skin, spleen, muscle, adrenal, eye, prostate and testis to maintain and regulate the cellular redox state $(21,135$, $161,171)$. It is also necessary for prenatal transport of the ascorbic acid across the placenta (146).

Both SVCT1 and SVCT2 cotransport $\mathrm{Na}^{+}$and AsC with a 2:1 stoichiometry along the electrochemical $\mathrm{Na}^{+}$gradient and show a binding order of $\mathrm{Na}^{+}-\mathrm{Asc}-\mathrm{Na}^{+}$(Fig. 3) $(63,102)$.

In the case of oral administration, the plasma concentration of vitamin $C$ is tightly controlled. Plasma vitamin C concentration reaches a plateau by the increasing oral doses (124). It can be explained by two factors: First, as we described above, the capacity of the Asc transporters is limited (as it is the case for all transport proteins). Second, the expression of SVCTS is fine-tuned by their own ligand and by the redox state of the cell. The uptake of AsC and the expression of SVCT1 was significantly decreased upon elevated Asc levels (101). A similar self-regulatory role for Asc was demonstrated for SVCT2 in platelets, where SVCT2 expression showed Asc-concentration dependence at the translational level (136). It is not exactly clear whether vitamin $C$ acts on its own carrier directly or indirectly by altering the redox state of the cell. This is a real dilemma since skeletal muscle cells modulated the expression of SVCT2 carrier according to their redox balance. The mRNA and protein levels of SVCT2 were up-regulated in $\mathrm{H}_{2} \mathrm{O}_{2}$-treated myotubes, while antioxidant supplementation lowered the expression of SVCT2 (137). 
The investigation of the transcriptional regulation of human SVCT1 revealed that the basal transcription of SVCT1 depends on the binding of hepatic nuclear factor 1 (HNF-1) to the promoter of SVCT1 (111). HNF-1 sites play important role in ascorbic acid deprivation and supplementation on the activity and regulation of Asc transport systems (131). The promoter of SVCT2 binds Yin Yang-1 (YY1) and interacts with specificity protein 1/3 (Sp1/Sp3) elements in the proximal promoter region. YY1 with Sp1 or Sp3 synergistically enhanced the promoter activity as well as the endogenous SVCT2 protein expression (130). Although Asc is absorbed along the entire length of the human intestine (103), it was reported that the carrier-mediated Asc uptake is significantly lower in the colon than in the jejunum (148). It was associated with significantly lower level of expression of SVCT1 and 2 at both protein and mRNA levels. The lower level of Asc uptake in colon can be at least partially attributed to differential levels of transcription of the SLC23A1 and SLC23A2 genes between these regions. Changes were found in both transcription factor abundance and histone modifications relevant to the control of SVCT1 and 2 expression level in the colon and jejunum. As we saw, the basal activity of SVCT1 and SVCT2 promoters are regulated by HNF-1 $\alpha$ and Sp1 $(111,130,131)$. The levels of both transcription factors (HNF-1 $\alpha$ and Sp1) were significantly lower in the colon compared to the jejunum (148). Furthermore, two euchromatin markers for both genes were lower and a heterochromatin marker for SVCT1 was higher in the colon compared to the jejunum (148). At this point it is worth to note that vitamin $\mathrm{C}$ has been shown to regulate the epigenome, suggesting a possible role of vitamin $\mathrm{C}$ itself in the regional expression of genes.

As it can be expected, polymorphisms in the genes encoding SVCTs are strongly associated with plasma Asc levels and likely impact tissue cellular vitamin C status. A few SNPs in SLC23A1 caused lower SVCT1 activity and consequently lower plasma or serum AsC concentration. Unfortunately, studies are lacking on the possible effects of genetic variation in SLC23A2 on cellular vitamin C status (112).

The picture on vitamin $\mathrm{C}$ transporters is much more blur at subcellular level. The endoplasmic reticulum (ER) in human cells should possess transporter(s) to ensure the substrate supply of intraluminal vitamin C utilizing enzymes. However up to date, no Asc or DHA transporter have been identified at molecular level in the ER. The preferential uptake 
of DHA was found in mammalian microsomal vesicles in a functional study. The properties of transport suggested the involvement of GLUT-type transporter(s) (12). According to this assumption, almost no Asc uptake could be observed; furthermore, the oxidation of Asc to DHA was a prerequisite for its uptake (38). The reported microsomal membrane associated Asc oxidase activity can be the initiator of the uptake of vitamin C (153). More recently, GLUT10 was proposed to act as an ER DHA transporter (142), but the fact that its inherited deficiency is restricted to certain cell types, suggests that other ER DHA transporters may exist (Fig. 3).

The initial observation of mitochondrial glucose and DHA uptake in plant cells (151) raised the possibility of the role of GLUT family in mitochondrial vitamin C (DHA) transport. Indeed GLUT1 was found to be localized in the mitochondrial inner membrane of human kidney (293T) cells (81). Later, another member of the GLUT family, namely GLUT10 was found to be localized in the mitochondrial inner membrane of rat aortic smooth muscle cells (3T3-L1 and murine adipocytes (A10) (90). The mitochondrial uptake and accumulation of the reduced form, Asc could not be observed in mitochondria from human kidney cells nor from rat liver tissue $(81,93)$. Thus DHA was considered to be the transported form of vitamin C and GLUT family members were thought to mediate its transport through the mitochondrial membrane. However, recently the mitochondrial expression of SVCT2 and $\mathrm{Na}^{+}$-dependent mitochondrial Asc uptake were revealed by western blot experiments $(7,66)$. The association of SVCT2 protein with mitochondria was also confirmed by both co-localization experiments and immunoblotting of proteins extracted from highly purified mitochondrial fractions (119). At the same time, no GLUT10 expression could be observed and the mitochondrial localization of GLUT1 could also not be corroborated (119), thus the role of GLUTs in mitochondrial vitamin C transport (at least in the investigated HEK-293 cell line) was queried. Very recently, the role of GLUT1 as a mitochondrial DHA transporter could be confirmed by in silico prediction tools; however, the mitochondrial presence of GLUT10 is not likely at this moment, since this transport protein got by far the lowest mitochondrial localization scores. The latest experimental observations on the mitochondrial presence of SVCT2 was also verified by computational prediction tools (Fig. 3) (149). 
Finally, the localization and targeting of GLUT8 is conspicuously similar to the sorting mechanisms reported for lysosomal proteins (44). According to this observation GLUT8 has been found to be associated with endosomes and lysosomes (138). Since GLUT8 is known to transport DHA (34) it is likely that DHA transport in the lysosomes is occurred via GLUT8.

Due to the saturation and tight regulation of Asc transporters, the maximum uptake of vitamin C can only be reached at lower oral doses, then it declines with increasing intake. This finding was confirmed by experimental results as well as pharmacokinetic models $(66$, $94,126)$. On the grounds of this limitation of Asc uptake the oral intake of mega dose of Asc does not accompanied by elevated plasma levels. As we will discuss in the next chapter, pharmacological plasma concentrations of vitamin C can only be reached via intravenous administration of the vitamin (124).

\subsection{The regulation of ascorbate concentrations in seed plants and green algae}

The biosynthesis of Asc in higher plants and green algae proceeds mostly via the SmirnoffWheeler pathway, during which no ROS are produced, which is in contrast with the animallike pathway (reviewed recently by $(19,173)$ ) (Fig. 4). There may be three alternative pathways in plants, with contested significance, including (i) the L-gulose pathway (176), (ii) the galacturonate ("pectin scavenging") pathway (2), (iii) and the animal-like Asc biosynthesis (myo-inositol) pathway (98).

The Smirnoff-Wheeler pathway involves the conversion of D-mannose into Asc via a series of L-galactose containing intermediates. The final step, the oxidation of L-galactono-1,4lactone into Asc is catalyzed by galactono-1,4-lactone dehydrogenase, associated with the mitochondrial complex I (113).

The rate of Asc biosynthesis is largely determined by the expression level of VTC2, encoding GDP-L-galactose phosphorylase, which strongly responds to high light and is regulated by the circadian clock in higher plants (46). Asc biosynthesis is also dependent on photosynthetic electron transport (83) via poorly understood mechanisms (Fig. 4A). Under stress conditions, including UV-B (61), ozone (25), salt (71) and high light stress $(46,116)$, a 
two- to three-fold increase of Asc content can be observed on the timescale of days in seed plants.

Because of the beneficial properties of Asc, both on plant physiology and as an essential nutrient for humans, there has been a large number of attempts to increase its concentration in plant leaves and fruits. The most obvious way is to overexpress the enzymes participating in its biosynthesis. However, this resulted in moderate success, maximum 3-fold increase in leaf Asc content when using stable overexpression (reviewed by (96)); on the other hand, transient overexpression of both kiwifruit GDP-L-galactose phosphorylase and GDP-mannose-3', 5'-epimerase in tobacco leaves resulted in up to an 8fold increase in Asc content (20). The reason behind the moderate increase achieved upon stable transformation of the biosynthesis pathway genes may be the strong feedback regulation of AsC on VTC2 expression (46) and on GDP-L-galactose phosphorylase translation (88).

Asc biosynthesis and its regulation are less-well studied in non-vascular plants. Bryophytes and green algae contain about 100-fold less Asc than higher plants (reviewed by $(62,173)$ ). Therefore, the question arises how these organisms can cope with environmental stress conditions if possessing such low Asc contents. It was shown recently that in contrast to seed plants, algae lack a negative feedback regulation in the physiological concentration range, and instead, a feedforward regulation was found, enabling a very rapid and manifold increase in Asc biosynthesis upon stress conditions (168) (Fig. 4B).

The amount of Asc is regulated not only at the level of biosynthesis, but also by its regeneration. Asc becomes oxidized to MDA in various reactions, e.g. during the scavenging of ROS and organic radicals; inside the thylakoid lumen, MDA is produced by VDE and upon electron donation by Asc to PSII or PSI. In the chloroplast stroma, MDA can be reduced back to Asc by ferredoxin (Fd) or by MDAR both in the chloroplast stroma and the cytosol (5). Inside the thylakoid lumen, in the absence of $\mathrm{Fd}$ and MDAR, MDA spontaneously disproportionates to Asc and DHA (105). Following this reaction, DHA is transported across the thylakoid lumen to the stroma via yet unidentified Asc transporters (51). DHAR plays essential roles in maintaining the Asc concentration at a desired level 
both in the chloroplast and in other cellular compartments: if DHA does not become reduced, it undergoes irreversible hydrolysis (see below), which results in a decrease of the Asc pool. Asc being a major reductant in plants, DHAR also contributes to the regulation of the cellular redox state.

By overexpressing DHAR in higher plants, approx. 3-fold increase in total Asc content could be achieved, which resulted in a better growth and higher resistance to heat stress and methylviologen treatment (172). On the other hand, DHAR overexpressing plants are more susceptible to drought stress, since the DHA/Asc ratio strongly affects the amount of $\mathrm{H}_{2} \mathrm{O}_{2}$, which is a signaling molecule with a strong effect on stomatal opening (31). Increasing the amount of Asc relative to DHA resulted in a strongly decreased $\mathrm{H}_{2} \mathrm{O}_{2}$ content, thus the regulation of stomatal closure was disturbed and these plants became sensitive to drought stress (31).

Asc content in plants may be also controlled by its degradation. The major Asc degradation pathway in seed plants occurs via DHA, yielding oxalate and L-threonate $(65,160)$; in the Vitaceae family, Asc may also get degraded via the L-tartarate pathway. Using $\left[{ }^{14} \mathrm{C}\right]$ Asc labelling, Truffault et al. (160) found that Asc degradation was stimulated by darkness, and the degradation rate was approx. $63 \%$ of the Asc pool per day in tomato leaves, which was constant and independent of the initial Asc and DHA concentrations.

On the other hand, it was found that in green algae, the rate of Asc degradation is very rapid: upon a light-to-dark-transition, it occurs with a halftime of approx. 2 hours (168); however, the pathway of Asc degradation is unknown. It also remains to be investigated whether the rate of Asc degradation is a controlled process and if it participates in the maintenance of optimal Asc level in higher plants and algae; it also cannot be excluded that Asc degradation has a recycling role.

Asc cannot freely diffuse through biological membranes because of its size and negative charge at physiological $\mathrm{pH}$ and most probably the neutral DHA is also insufficiently lipophilic to efficiently cross lipid membranes by simple diffusion (132). The last step of Asc biosynthesis takes place in the mitochondria; therefore, Asc transporters are most likely essential for maintaining optimal Asc concentrations in the various cellular compartments, 
including the chloroplast, the nucleus, the cytosol, cell wall and the vacuole (51) (Fig. 4A). It has also been demonstrated that Asc is transported throughout the plant via the phloem from source to sink tissues (56).

DHA is taken up via the plasma membrane and the transporter is distinct of glucose carriers, whereas a mitochondrion-localized DHA transporter shows similarities to glucose transporters (150). However, the molecular identity of these transporters remains to be unraveled. Twelve members of the Arabidopsis nucleobase-Asc transporter family have been molecularly characterized (109), however, no evidence has been found for Asc transport activity for any of these proteins. A substantial breakthrough was achieved by Miyaji et al. (115), who have identified a chloroplast-localized Asc transporter, called AtPHT4;4 (Fig. 4A). AtPHT4;4 knockout mutants exhibited moderately reduced levels of Asc in the chloroplast, resulting in decreased non-photochemical quenching. However, plant growth and photosynthetic efficiency were not affected, suggesting that AtPHT4;4 may not be the only chloroplast membrane Asc transporter. In addition, it is very likely that there are Asc and DHA transporters located in the thylakoid membrane as well, to allow for an efficient regeneration of DHA and a sustained Asc supply into the thylakoid lumen (51). Miyaji et al. (115) suggested that AtPHT4;1 may be a thylakoid membrane localized Asc transporter, but it was shown before long that this is not the case (80). In green algae and other photosynthesizing unicellular species, no Asc transporters have been identified so far.

The elucidation of additional Asc and DHA transporter proteins both in the chloroplast and other cellular membrane system warrants further investigations. The transporters are likely to play a regulatory role in setting the appropriate Asc concentration in each cellular compartment. We also note that identifying Asc transporters may be a key to substantially increase the Asc content of plants. This notion is based on the fact that an alpine plant, Soldanella alpina accumulates approx. 10 times more Asc in its leaves than low-land plants, but most of this Asc is stored in the vacuole, most probably as a safety storage against UV damage; together with this, the chloroplastic Asc concentration of S. alpina is in the same range as in Arabidopsis and spinach, i.e. about $25 \mathrm{mM}$ (16). 


\section{Potentially harmful effects of ascorbate in animals and plants}

\subsection{The pro-oxidant role of ascorbate and its therapeutic usage in humans}

In the course of the Haber-Weiss reaction the toxic hydroxyl radical can be generated from the less reactive superoxide and hydrogen peroxide (82). In biological systems, this reaction is thermodynamically unfavourable, and it needs a metal ion catalyst to occur. In the Fenton reaction ferrous iron reacts with $\mathrm{H}_{2} \mathrm{O}_{2}$ to generate hydroxyl radical and ferric iron (Eq. 1). The ferrous iron can also readily react with $\mathrm{O}_{2}$, reducing it to superoxide radical (Eq. 2), which in turn dismutes to $\mathrm{H}_{2} \mathrm{O}_{2}$ and $\mathrm{O}_{2}$ (Eq. 3) (48). In vitro, Asc, as an excellent electron donor, can reduce ferric iron to ferrous iron while being oxidized to Asc radical (Eq. 4). By this means, Asc contributes to the continuous generation of ROS. Not accidentally, iron salt and Asc mixtures have been used in vitro to induce lipid peroxidation and different oxidative damages (91).

$$
\begin{aligned}
& \mathrm{Fe}^{2+}+\mathrm{H}_{2} \mathrm{O}_{2} \rightarrow \mathrm{Fe}^{3+}+\mathrm{OH}^{-}+\mathrm{OH}^{-} \\
& \mathrm{Fe}^{2+}+\mathrm{O}_{2} \rightarrow \mathrm{Fe}^{3+}+\mathrm{O}_{2}^{-\cdot} \\
& \text { Eq. } 2 \\
& \mathrm{O}_{2}{ }^{--}+\mathrm{O}_{2}{ }^{-{ }^{-}}+2 \mathrm{H}^{+} \rightarrow \mathrm{H}_{2} \mathrm{O}_{2}+\mathrm{O}_{2} \\
& \text { Eq. } 3 \\
& \mathrm{Fe}^{3+}+\mathrm{Asc}^{-} \rightarrow \mathrm{Fe}^{2+}+\mathrm{Asc}^{--}
\end{aligned}
$$$$
\text { Eq. } 1
$$$$
\text { Eq. } 4
$$

Therefore, in biological systems, in the course of the formation of ascorbyl radical, Asc can donate an electron to a transition metal such as iron or copper. The reduced metal is capable of reacting with $\mathrm{O}_{2}$ forming superoxide anion and then $\mathrm{H}_{2} \mathrm{O}_{2}$. In the presence of higher $(\mathrm{mM})$ concentrations of $\mathrm{Asc}, \mathrm{H}_{2} \mathrm{O}_{2}$ can readily react with further transition metal ions in the Fenton reaction, to form the highly reactive, cytotoxic hydroxyl radical (82).

It is reasonable to presume that the tight control of Asc concentration via its strictly regulated transport provides the background to prevent the continuous tissue exposure to 
high concentrations of $\mathrm{H}_{2} \mathrm{O}_{2}$. However, the temporal bypass of this tight control by parenteral administration of Asc gives the possibility to form $\mathrm{H}_{2} \mathrm{O}_{2}$ in discrete, well-defined time periods, decreasing the likelihood of harm, and provides a pharmacologic basis for therapeutic use of Asc (127).

The generated $\mathrm{H}_{2} \mathrm{O}_{2}$ and hydroxyl radical may induce DNA injury that is followed by the activation of poly(ADP-ribose) polymerase-1, the depletion of $\mathrm{NAD}^{+}$and ATP (1). Glutathione peroxidase (GPX), peroxiredoxins and thioredoxin certainly take a major part in the removal of $\mathrm{H}_{2} \mathrm{O}_{2}$. Upon the recycling of peroxiredoxins and the action of GPX, GSH is oxidized to glutathione disulphide (GSSG). The generated GSSG and oxidised thioredoxin can be re-reduced by NADPH, which in turn is regenerated from glucose via the pentose shunt (Fig. 5). Hence the regeneration of NADPH may use up glucose, preventing ATP production (141).

Cancer cells compared to normal cells can be characterized by increased steady-state levels of ROS (i.e. $\mathrm{O}_{2}{ }^{--}$and $\mathrm{H}_{2} \mathrm{O}_{2}$ ); furthermore they show increased susceptibility to glucose-deprivation induced cytotoxicity and oxidative stress $(3,6)$. These observations support the hypothesis that cancer cells increase glucose metabolism to compensate for excess metabolic production of ROS. This way the utilization of glucose by the enhanced NADPH requirement due to the enhanced GSH consumption may provide a biochemical target for selectively enhancing cytotoxicity and oxidative stress in human cancer cells (159).

In the light of the above observations it is not surprising that the exposure of different cancer cell lines to Asc up to the concentrations of $20 \mathrm{mM}$ for $1 \mathrm{~h}$ caused a $50 \%$ decrease in cell survival, while it did not affect the survival of normal human cells (28). In the case of human Burkitt's lymphoma cells (JLP-119) significant cell death could be observed at as low as $0.3 \mathrm{mM}$ of Asc concentration (28). The cytotoxicity of Asc on A2780 human ovarian cancer cells could also be characterized by similarly low $0.3 \mathrm{mM}$ of IC50 (100). The cytotoxic effect of high dose Asc on different cancer cell lines have been demonstrated by various research groups $(28,42,84,127)$. These studies show that Asc present at high concentrations can induce $\mathrm{H}_{2} \mathrm{O}_{2}$ generation, which is preferentially cytotoxic to cancer 
cells. Cell death was dependent on $\mathrm{H}_{2} \mathrm{O}_{2}$ production mediated by extracellular Asc oxidation (Fig. 5) $(28,30,42,84,127)$. The $\mathrm{H}_{2} \mathrm{O}_{2}$ mediated Asc toxicity could be alleviated by exogenous catalase or adenoviral-mediated overexpression of catalase or glutathione peroxidase 1 (139). These results suggested that Asc given parenterally (to bypass the tight control of oral absorption discussed in the previous section) can be an effective antitumour agent. Indeed, the parenteral administration of Asc decreased the growth rate of a murine hepatoma (167), ovarian, pancreatic, and glioblastoma tumours established in mice (30). Parenteral administration of Asc resulted in a 12-fold higher ascorbyl radical level in the extracellular fluid than in the blood (29). Since $\mathrm{H}_{2} \mathrm{O}_{2}$ is immediately scavenged in blood (77), elevated level of $\mathrm{H}_{2} \mathrm{O}_{2}$ due to parenteral Asc administration could only be measured in the extracellular fluid (29). By this means, Asc at high doses can be a prodrug for the formation of ascorbyl radical and $\mathrm{H}_{2} \mathrm{O}_{2}$ in the extracellular space but not in blood.

The effects of various chelators suggests that intracellular metals play an important role in Asc toxicity. The pre-incubation of human DU145 cells with deferoxamine, a cell permeable metal chelator, prevented the loss of viability of tumour cells exposed to high concentration of Asc (167). The DNA damage in high dose Asc treated lymphocytes could also be prevented by iron and copper chelators (162). The high dose Asc induced cytotoxicity of neuroblastoma cell lines was associated with increased ferritin release and increased lactate production. The elevated ferritin production and secretion can serve as a continuous iron source for Asc-mediated $\mathrm{H}_{2} \mathrm{O}_{2}$ production (Fig. 5) (42). The free or labile (loosely bound) iron is highly cytotoxic, thus it is usually bound to proteins, such as ferritin $(15,143)$. ROS and Asc can disrupt the cellular iron metabolism that leads to increased labile iron pool (Fig. 5) (8, 23, 74). Cancer cells, in general can be characterized by elevated intracellular labile iron level (156). In addition to the higher basal level of labile iron in glioblastoma and non-small-cell, lung cancer cells showed significant dose-dependent Ascinduced elevation in cellular labile iron pool that were not seen in normal human astrocytes or normal human bronchial epithelial primary cells (139). The observed loss of Fe-S cluster protein activity and the accompanying elevation of labile iron pool could be prevented by the overexpression of catalase implicating $\mathrm{H}_{2} \mathrm{O}_{2}$ as the causative agent in Asc-induced increases of labile iron pool (Fig. 5) (139). The elevated mitochondrial ROS 
caused elevated labile iron pool, which could lead to more intensive oxidation of Asc to generate more $\mathrm{H}_{2} \mathrm{O}_{2}$ that caused a further elevation of labile iron pool of cancer cells compared to normal cells. The high concentration of $\mathrm{H}_{2} \mathrm{O}_{2}$ in the presence of high labile iron facilitates the occurrence of Fenton reaction that generate the highly toxic hydroxyl radical (Fig. 5) (139). In normal cells with lower basal and Asc mediated $\mathrm{H}_{2} \mathrm{O}_{2}$ and labile iron levels, $\mathrm{H}_{2} \mathrm{O}_{2}$ is metabolized quickly before it can take part in pro-oxidant reactions. Therefore, Asc is not toxic for normal cells $(28,139)$. The observed safety of high dose Asc in animal xenograft $(30,100,167)$ and human $(47,123)$ studies can also be explained by this phenomenon.

The cytotoxic effect of Asc on cancer cells is rather well documented; however, its precise cell death mechanism has not been elucidated yet. The cell death of cancer cells due to high dose Asc treatment has been presumed by several studies to be apoptotic (Fig. 5) (26, $70,78,95)$. The induction of apoptosis in B16F10 murine melanoma was assessed by phosphatidylserine externalization using FITC-annexin V binding (78). The reduction in the mitochondrial membrane potential during cell death (apoptosis) and cytochrome-c release from mitochondria could also be observed. However, cell death could not be inhibited by z-IETD-fmk indicating that Asc-induced apoptosis was not mediated by caspase-8 (78). In another study, Hong et al. (70) found that Asc induced cell death through the apoptosisinducing factor (AIF) in human breast cancer cells (SK-BR3, Hs578T), but caspase (3 and 9) cleavage was also not induced (70). On the other hand, using a fluorescence-based pancaspase activity assay kit, Carosio et al. (26) found general and specific caspase activity (caspase-1,-2,-3,-6,-7,-8,-9,-10) in neuroblastoma cells treated by high dose Asc (26). The apoptotic cell death was also assessed by FITC-annexin $V$ and mitochondrial transmembrane potential assays. It should also be noted that this study suggested that iron depletion is responsible for the Asc-induced cell death in neuroblastoma cells that is controversial with all other studies. Flow cytometric analysis of Lin et al. (95) showed that Asc induced significant cell cycle arrest and apoptosis in human melanoma (A375.S2) cell line in a dose-dependent manner. Induction of apoptosis involved an increase in the levels of p53, p21, cellular $\mathrm{Ca}^{2+}$, a decrease in mitochondrial membrane potential and activation of caspase $3(95)$. 
Beside apoptotic cell death, autophagy has also been proposed as a potential high dose Asc induced cell death mechanism (Fig. 5). Pancreatic cancer cells treated with high dose Asc demonstrated an increase in LC3-II immunoreactive protein (36). This increase in LC3-II and the caspase independent cell death could be reversed by a pre-treatment of the cells with catalase suggesting that the Asc-induced induction of autophagy is mediated by the generated $\mathrm{H}_{2} \mathrm{O}_{2}$. Similarly, Chen et al. found that high dose Asc treatment depleted ATP and induced autophagy in prostate cancer cells, where autophagy pathway could be detected by the processing of LC3 to LC3-II and the redistribution of LC3-II to the surface of autophagosomes (27). Similarly Fukui et al. showed that high dose Asc induced the formation of autophagosomes and the presence of autophagy inhibitors suppresses Ascinduced cell death (58). The above results were corroborated by Du et al., who found that the treatment of pancreatic cancer cells (MIA PaCa-2) with high dose Asc induced a caspase-independent cell death that was associated with autophagy (49). The involvement of autophagy in cell death was demonstrated by an increase of LC3-II 4-6 hours after the Asc treatment. They also ruled out that PARP-1 activation and ATP depletion contribute to Asc induced cell death. The inhibition of caspases did not reverse the percentage of necrotic or apoptotic cells with Asc (49). These findings also suggests a necrotic component of the Asc induced cell death.

It is interesting that the studies proposing apoptotic cell death are dated before 2010 and the studies propose autophagic cell death are dated after 2010. Moreover, it is also worth to note that the mechanism of cell death by high dose Asc treatment depends on the cell type, on the applied concentration, on the duration of Asc treatment, on the composition of culture media and certainly on several other conditions.

In a study on nine breast cancer cell lines it was found that functional SVCT-2 sensitizes breast cancer cells to autophagic damage by increasing the Asc concentration and intracellular ROS production (69). Intriguingly, in another study on cholangiocarcinoma cells SVCT-2 expression was also inversely correlated with IC50 values of Asc. The knockdown of SVCT-2 dramatically alleviated DNA damage, ATP depletion, and inhibition of mTOR pathway induced by Asc. Furthermore, SVCT-2 knockdown endowed cholangiocarcinoma cells with the resistance to Asc treatment (169). These observations 
suggest that the intracellular ROS formation may also contribute to the Asc mediated cytotoxicity (Fig. 5).

The observations that ferroptosis is an iron-dependent ROS mediated cell death mechanism that could be suppressed by co-treatment with the iron chelator deferoxamine (45), and that it was not consistently modulated by inhibitors of caspase, cathepsin, or calpain proteases (z-VAD-fmk, E64d, or ALLN) (45), and autophagy is involved in its induction through the elevation of labile iron pool (60) lead us to hypothesize that ferroptosis (at least partly) may responsible for the high Asc dose-induced cytotoxicity in cancer cells.

\subsection{Negative effects of high ascorbate concentration in plants: interference with ROS signaling, redox balance and its pro-oxidant property}

It has been long considered that ROS have negative effects on cellular functions and cell viability in plants. However, there is a paradigm shift going on, as more and more evidence demonstrate that ROS production linked to signaling is required for a plethora of plant responses to developmental and environmental changes (reviewed by $(54,98)$ ). It was discovered recently that basal level of ROS is even required to support life (reviewed by $(75,114))$. ROS may act directly by oxidizing e.g. certain regulatory factors influencing protein translation and they may lead to changes in cellular redox potential that will impact various redox-sensitive proteins. It has been also shown that Asc regulate the activity of chloroplastic APXs, which has immediate effects on the $\mathrm{H}_{2} \mathrm{O}_{2}$ levels, acting as a retrograde signal from the chloroplast to the nucleus (reviewed by (107)). Another example is the above-mentioned overexpression of DHAR, which resulted in several-fold increase in Asc content, but as a consequence, the plants became less adaptive to drought stress due to impaired $\mathrm{H}_{2} \mathrm{O}_{2}$ signaling (31). In this context, the role of the plant antioxidant system is to control or mitigate the amount of cellular ROS, rather than completely eliminating them. This may also mean that plants have developed various control mechanisms to avoid the overproduction of antioxidants, such as the negative feedback mechanism exerted by Asc on VTC2 expression and translation (46, 88) (Fig. 4A). Regarding 
the generation of plants with elevated Asc content, this may mean that even if we managed to overcome the feedback regulatory mechanisms to control Asc biosynthesis, the plants would not show increased stress tolerance; instead, adaptation responses may be hampered. The solution may be to overexpress the putative vacuolar Asc transporters (51) (Fig. 4A), in addition to overexpressing Asc biosynthesis genes, which would allow the accumulation of Asc in the vacuole and the physiological Asc concentrations in the other cellular compartments (chloroplast, cytosol and mitochondria) would be maintained.

Another issue when considering the possible negative roles of Asc, is its reducing property. Although, in plant research reductive stress is rarely considered, one may imagine that the accumulation of reductants may alter cellular redox balance, which is of high importance to enzymes under redox control. Changing of redox balance within the chloroplast may also severely disturb a large number of physiological processes. One example, discovered recently, is that upon sulphur deprivation of green algae, Asc can accumulate so strongly (to the $\mathrm{mM}$ range) that it over-reduces and thereby inactivates the Mn-cluster of the OEC (120) (Fig. 6A). Under normal growth conditions, this does not occur, because the Asc content is very low in green algae (approx. $100 \mu \mathrm{M},(120,164))$. On the other hand, seed plants have acquired high Asc concentrations during evolution to cope with the continuously changing environment (62), thus the question may be raised by which mechanism the OEC in seed plants is protected from the reducing effect of Asc. It has been shown earlier that in the absence of the extrinsic OEC proteins, the Mn-cluster becomes accessible to Asc, resulting in its inactivation (154). There are significant structural differences between the extrinsic proteins of seed plants and algae, among which the two types of PSBO proteins are shown in Figs. $6 \mathrm{~B}$ and C; it is conceivable that during evolution the PSBO protein has evolved to protect the OEC against the reducing effect of Asc. As pointed out earlier, once the OEC is inactive, Asc provides electrons to the photosynthetic electron transport chain via $\mathrm{Tyrz}^{+}$, which has a moderate effect in mitigating donor-side induced photoinhibition $(120,157,158)$ (Fig. 6A).

In addition to its antioxidant character, the pro-oxidant nature of Asc has been also described, although rarely considered. In plants, the Fenton reaction (Eqs. 1-4) was shown to occur isolated thylakoid membranes (163) and it occurs also in vivo in the apoplast, 
where it causes the non-enzymatic scission of polysaccharides, leading to cell-wall loosening during fruit ripening $(50,57)$ and cell expansion $(81,119)$. It has been also reported that externally supplied Asc results in oxidative stress in intact Arabidopsis leaves (129). The number of studies on the pro-oxidant effect of Asc in plants is very limited, especially compared to the field of mammalian research and the topic certainly merits further investigations.

$\mathrm{H}_{2} \mathrm{O}_{2}$ is formed also during Asc degradation (65), which may contribute to the pro-oxidant effect of Asc. Therefore, it is conceivable that upon stress conditions, when the oxidation of Asc proceeds at a higher rate than its regeneration, substantial Asc degradation occurs and along with the production of $\mathrm{H}_{2} \mathrm{O}_{2}$, thus the stress situation is aggravated.

\section{Conclusions}

To maintain the cellular concentration of Asc in an optimum range is of vital importance, because Asc may interfere with regulatory mechanisms by various means and may even cause or enhance oxidative stress.

In plants, the most obvious mechanism of maintaining an optimal Asc concentration is the regulation of its biosynthesis: a number of studies show that Asc biosynthesis is regulated by feedback mechanisms, both on the level of gene expression and protein translation. Other regulatory points of Asc concentration may be its degradation and inter- and intracellular transport; both of these mechanisms certainly warrant further investigations. Considering that high Asc levels may have negative effects on cellular functions is very important also when aiming at enhancing the Asc contents of leaves and fruits. A feasible solution may be to increase the Asc levels in specific storage organs or in the vacuole, in a similar manner as it can be often observed in fruits and leaves possessing extraordinarily high Asc contents.

On the contrary to plants, the key regulatory element of Asc level in humans and human cells is its transport. As it was delineated, Asc can reduce transition metals and the 
reduced metal is capable of reacting with $\mathrm{O}_{2}$ forming superoxide anion and then $\mathrm{H}_{2} \mathrm{O}_{2}$. In the presence of high concentration of $\mathrm{Asc}, \mathrm{H}_{2} \mathrm{O}_{2}$ can readily react with further transition metal ions to form the highly reactive and cytotoxic hydroxyl radical. The tight control of Asc concentration in the human body and cells via its transporters provides the background to prevent the continuous tissue exposure to high concentrations of $\mathrm{H}_{2} \mathrm{O}_{2}$. Normal cells, in comparison with cancer cells, can be characterized by lower basal and Ascmediated $\mathrm{H}_{2} \mathrm{O}_{2}$ and labile iron levels, thus $\mathrm{H}_{2} \mathrm{O}_{2}$ is metabolized quickly before it can take part in pro-oxidant reactions. The temporal bypass of this tight control by parenteral administration of Asc gives the possibility to form $\mathrm{H}_{2} \mathrm{O}_{2}$ in discrete, well-defined time periods, which decreases the likelihood of harm and provides a pharmacologic basis for anti-tumour therapeutic use of Asc. Two crucial problems are waiting to be clarified in the future. The exact mechanism of high dose Asc induced cell death that can help us to improve its therapeutic role. The other is the clarification of subcellular Asc transport in both humans and plants. This can shed more light on the regulation of Asc levels and its potential pro- or antioxidant roles in various subcellular compartments, where Asc has special functions, such as in the mitochondria, chloroplast and endoplasmic reticulum.

\section{Acknowledgements}

This work was supported by the Lendület/Momentum Programme of the Hungarian Academy of Sciences (LP-2014/19), the National, Research and Development Office (NN 114524, K 105416, K 123752) and MedinProt Protein Excellence foundation. Tamás Lőrincz is a Gedeon Richter Plc Talentum fellowship recipient.

André Vidal-Meireles (Biological Research Centre Szeged) is acknowledged for the assistance with the preparation of Fig. 6.

\section{Author Disclosure Statement}

No competing financial interests exist. 


\section{References}

1. Adachi T, Nonomura S, Horiba M, Hirayama T, Kamiya T, Nagasawa H, and Hara H. Iron stimulates plasma-activated medium-induced A549 cell injury. Sci. Rep. 6: 20928, 2016.

2. Agius F, González-Lamothe R, Caballero JL, Muñoz-Blanco J, Botella MA, and Valpuesta V. Engineering increased vitamin C levels in plants by overexpression of a Dgalacturonic acid reductase. Nat. Biotechnol. 21: 177-81, 2003.

3. Ahmad IM, Aykin-Burns N, Sim JE, Walsh SA, Higashikubo R, Buettner GR, Venkataraman S, Mackey MA, Flanagan SW, Oberley LW, and Spitz DR. Mitochondrial O2.- and H2O2 mediate glucose deprivation-induced cytotoxicity and oxidative stress in human cancer cells. J. Biol. Chem. 280: 4254-4263, 2005.

4. Arrigoni O, and De Tullio MC. Ascorbic acid: much more than just an antioxidant. Biochim. Biophys. Acta 1569: 1-9, 2002.

5. Asada K. Production and scavenging of reactive oxygen species in chloroplasts and their functions. Plant Physiol. 141: 391-396, 2006.

6. Aykin-Burns N, Ahmad IM, Zhu Y, Oberley LW, and Spitz DR. Increased levels of superoxide and $\mathrm{H} 2 \mathrm{O} 2$ mediate the differential susceptibility of cancer cells versus normal cells to glucose deprivation. Biochem. J. 418: 29-37, 2009.

7. Azzolini C, Fiorani M, Cerioni L, Guidarelli A, and Cantoni O. Sodium-dependent transport of ascorbic acid in U937 cell mitochondria. IUBMB Life 65: 149-153, 2013.

8. Baader SL, Bill E, Trautwein AX, Bruchelt G, and Matzanke BF. Mobilization of iron from cellular ferritin by ascorbic acid in neuroblastoma SK-N-SH cells: An EPR study. FEBS Lett. 381: 131-134, 1996.

9. Ball GFM. Ascorbic acid | Physiology. Encycl. Food Sci. Nutr. 324-332, 2003.

10. Ballottari M, Alcocer MJP, D'Andrea C, Viola D, Ahn TK, Petrozza A, Polli D, Fleming GR, Cerullo G, and Bassi R. Regulation of photosystem I light harvesting by zeaxanthin. 
Proc. Natl. Acad. Sci. 111: E2431-E2438, 2014.

11. Bánhegyi G, Benedetti A, Margittai É, Marcolongo P, Fulceri R, Németh CE, and Szarka A. Subcellular compartmentation of ascorbate and its variation in disease states. Biochim. Biophys. Acta - Mol. Cell Res. 1843: 1909-1916, 2014.

12. Bánhegyi G, Marcolongo P, Puskás F, Fulceri R, Mandl J, and Benedetti A. Dehydroascorbate and ascorbate transport in rat liver microsomal vesicles. J. Biol. Chem. 273: 2758-2762, 1998.

13. Barth C. The Timing of Senescence and Response to Pathogens Is Altered in the Ascorbate-Deficient Arabidopsis Mutant vitamin c-1. PLANT Physiol. 134: 1784-1792, 2004.

14. Bassan A, Borowski T, Schofield CJ, and Siegbahn PEM. Ethylene Biosynthesis by 1Aminocyclopropane-1-Carboxylic Acid Oxidase: A DFT Study. Chem. - A Eur. J. 12: 8835-8846, 2006.

15. Blatt J, Huntley D, and Eagon PK. Synthesis of ferritin by neuroblastoma. Cancer Biochem. Biophys. 11: 169-176, 1990.

16. Bligny R, and Aubert S. Specifities of Metabolite Profiles in Alpine Plants. Plants Alp. Reg. 99-120, 2012.

17. Boyer JC, Campbell CE, Sigurdson WJ, and Kuo SM. Polarized localization of vitamin C transporters, SVCT1 and SVCT2, in epithelial cells. Biochem. Biophys. Res. Commun. 334: 150-156, 2005.

18. Buffinton GD, and Doe WF. Altered ascorbic acid status in the mucosa from inflammatory bowel disease patients. Free Radic. Res. 22: 131-143, 1995.

19. Bulley S, and Laing W. The regulation of ascorbate biosynthesis. Curr. Opin. Plant Biol. 33: 15-22, 2016.

20. Bulley SM, Rassam M, Hoser D, Otto W, Schünemann N, Wright M, MacRae E, Gleave A, and Laing W. Gene expression studies in kiwifruit and gene over-expression in 
Arabidopsis indicates that GDP-L-galactose guanyltransferase is a major control point of vitamin C biosynthesis. J. Exp. Bot. 60: 765-778, 2009.

21. Bürzle $M$, Suzuki $Y$, Ackermann $D$, Miyazaki $H$, Maeda $N$, Clémençon $B$, Burrier $R$, and Hediger MA. The sodium-dependent ascorbic acid transporter family SLC23. Mol. Aspects Med. 34: 436-454, 2013.

22. Calcutt $\mathrm{G}$. The formation of hydrogen peroxide during the autoxidation of ascorbic acid. Experientia 7: 26, 1951.

23. Caltagirone A, Weiss G, and Pantopoulos K. Modulation of cellular iron metabolism by hydrogen peroxide. Effects of $\mathrm{H} 2 \mathrm{O} 2$ on the expression and function of iron-responsive element-containing mRNAs in B6 fibroblasts. J. Biol. Chem. 276: 19738-19745, 2001.

24. Camarena V, and Wang G. The epigenetic role of vitamin C in health and disease. Cell. Mol. Life Sci. 73: 1645-1658, 2016.

25. Caregnato FF, Bortolin RC, Divan Junior AM, and Moreira JCF. Exposure to elevated ozone levels differentially affects the antioxidant capacity and the redox homeostasis of two subtropical Phaseolus vulgaris L. varieties. Chemosphere 93: 320-330, 2013.

26. Carosio R, Zuccari G, Orienti I, Mangraviti S, and Montaldo PG. Sodium ascorbate induces apoptosis in neuroblastoma cell lines by interfering with iron uptake. Mol. Cancer 6: 55, 2007.

27. Chen P, Yu J, Chalmers B, Drisko J, Yang J, Li B, and Chen Q. Pharmacological ascorbate induces cytotoxicity in prostate cancer cells through ATP depletion and induction of autophagy. Anticancer. Drugs 23: 437-444, 2012.

28. Chen Q, Espey MG, Krishna MC, Mitchell JB, Corpe CP, Buettner GR, Shacter E, and Levine M. Pharmacologic ascorbic acid concentrations selectively kill cancer cells: action as a pro-drug to deliver hydrogen peroxide to tissues. Proc. Natl. Acad. Sci. U. S. A. 102: 13604-13609, 2005.

29. Chen Q, Espey MG, Sun AY, Lee J-H, Krishna MC, Shacter E, Choyke PL, Pooput C, Kirk $\mathrm{KL}$, Buettner GR, and Levine M. Ascorbate in pharmacologic concentrations selectively 
generates ascorbate radical and hydrogen peroxide in extracellular fluid in vivo. Proc. Natl. Acad. Sci. U. S. A. 104: 8749-8754, 2007.

30. Chen Q, Espey MG, Sun AY, Pooput C, Kirk KL, Krishna MC, Khosh DB, Drisko J, and Levine M. Pharmacologic doses of ascorbate act as a prooxidant and decrease growth of aggressive tumor xenografts in mice. Proc. Natl. Acad. Sci. 105: 11105-11109, 2008.

31. Chen Z, and Gallie DR. The Ascorbic Acid Redox State Controls Guard Cell Signaling and Stomatal Movement. Plant Cell 16: 1143-1162, 2004.

32. Chen Z, and Gallie DR. Induction of Monozygotic Twinning by Ascorbic Acid in Tobacco. PLoS One 7: e39147, 2012.

33. Corpe C, Tu H, Wang J, Eck P, Wang Y, Schnermann J, Faulhaber-Walter J, Nussbaum R, and Levine M. SVCT1 (SIc23a1) knock out mice: Slc23a1 as the vitamin C kidney reabsorptive transporter. FASEB J. 21: 2007.

34. Corpe CP, Eck P, Wang J, Al-Hasani H, and Levine M. Intestinal dehydroascorbic acid (DHA) transport mediated by the facilitative sugar transporters, GLUT2 and GLUT8. J. Biol. Chem. 288: 9092-9101, 2013.

35. Cruz-Rus E, Botella MA, Valpuesta V, and Gomez-Jimenez MC. Analysis of genes involved in I-ascorbic acid biosynthesis during growth and ripening of grape berries. J. Plant Physiol. 167: 739-748, 2010.

36. Cullen JJ. Ascorbate induces autophagy in pancreatic cancer. Autophagy 6: 421-422, 2010.

37. Curien G, Flori S, Villanova V, Magneschi L, Giustini C, Forti G, Matringe M, Petroutsos D, Kuntz M, and Finazzi G. The Water to Water Cycles in Microalgae. Plant Cell Physiol. 57: pcw048, 2016.

38. CSALA M, MILE V, BENEDETTI A, MANDL J, and BÁNHEGYI G. Ascorbate oxidation is a prerequisite for its transport into rat liver microsomal vesicles. Biochem. J. 349: 413415, 2000. 
39. Dall'Osto L, Cazzaniga S, Havaux M, and Bassi R. Enhanced Photoprotection by ProteinBound vs Free Xanthophyll Pools: A Comparative Analysis of Chlorophyll b and Xanthophyll Biosynthesis Mutants. Mol. Plant 3: 576-593, 2010.

40. Dall'Osto L, Holt NE, Kaligotla S, Fuciman M, Cazzaniga S, Carbonera D, Frank HA, Alric J, and Bassi R. Zeaxanthin Protects Plant Photosynthesis by Modulating Chlorophyll Triplet Yield in Specific Light-harvesting Antenna Subunits. J. Biol. Chem. 287: 4182041834, 2012.

41. del Río LA, and López-Huertas E. ROS Generation in Peroxisomes and its Role in Cell Signaling. Plant Cell Physiol. 57: pcw076, 2016.

42. Deubzer B, Mayer F, Kuçi Z, Niewisch M, Merkel G, Handgretinger R, and Bruchelt G. H2O2-mediated cytotoxicity of pharmacologic ascorbate concentrations to neuroblastoma cells: Potential role of lactate and ferritin. Cell. Physiol. Biochem. 25: 767-774, 2010.

43. Dhariwal KR, Hartzell WO, and Levine M. Ascorbic acid and dehydroascorbic acid measurements in human plasma and serum. Am. J. Clin. Nutr. 54: 712-716, 1991.

44. Diril MK, Schmidt S, Krauß M, Gawlik V, Joost H-G, Schürmann A, Haucke V, and Augustin R. Lysosomal localization of GLUT8 in the testis - the EXXXLL motif of GLUT8 is sufficient for its intracellular sorting via AP1- and AP2-mediated interaction. FEBS J. 276: 3729-3743, 2009.

45. Dixon SJ, Lemberg KM, Lamprecht MR, Skouta R, Zaitsev EM, Gleason CE, Patel DN, Bauer AJ, Cantley AM, Yang WS, Morrison B, and Stockwell BR. Ferroptosis: An irondependent form of nonapoptotic cell death. Cell 149: 1060-1072, 2012.

46. Dowdle J, Ishikawa T, Gatzek S, Rolinski S, and Smirnoff N. Two genes in Arabidopsis thaliana encoding GDP-I-galactose phosphorylase are required for ascorbate biosynthesis and seedling viability. Plant J. 52: 673-689, 2007.

47. Drisko JA, Chapman J, and Hunter VJ. The use of antioxidants with first-line chemotherapy in two cases of ovarian cancer. J. Am. Coll. Nutr. 22: 118-123, 2003. 
48. Du J, Cullen JJ, and Buettner GR. Ascorbic acid: Chemistry, biology and the treatment of cancer. BBA - Rev. Cancer 1-15, 2012.

49. Du J, Martin SM, Levine M, Wagner BA, Buettner GR, Wang S, Taghiyev AF, Du C, Knudson CM, and Cullen JJ. Mechanisms of ascorbate-induced cytotoxicity in pancreatic cancer. Clin. Cancer Res. 16: 509-520, 2010.

50. Dumville JC, and Fry SC. Solubilisation of tomato fruit pectins by ascorbate: a possible non-enzymic mechanism of fruit softening. Planta 217: 951-961, 2003.

51. Fernie AR, and Tóth SZ. Identification of the Elusive chloroplast ascorbate transporter extends the substrate specificity of the PHT family. Mol. Plant 8: 674-676, 2015.

52. Fotopoulos V, De Tullio MC, Barnes J, and Kanellis AK. Altered stomatal dynamics in ascorbate oxidase over-expressing tobacco plants suggest a role for dehydroascorbate signalling. J. Exp. Bot. 59: 729-737, 2008.

53. Foyer $\mathrm{CH}$, and Mullineaux PM. The presence of dehydroascorbate and dehydroascorbate reductase in plant tissues. FEBS Lett. 425: 528-529, 1998.

54. Foyer $\mathrm{CH}$, and Noctor G. Stress-triggered redox signalling: what's in pROSpect? Plant. Cell Environ. 39: 951-964, 2016.

55. Foyer $\mathrm{CH}$, and Shigeoka S. Understanding Oxidative Stress and Antioxidant Functions to Enhance Photosynthesis. PLANT Physiol. 155: 93-100, 2011.

56. Franceschi VR. L-Ascorbic Acid Is Accumulated in Source Leaf Phloem and Transported to Sink Tissues in Plants. PLANT Physiol. 130: 649-656, 2002.

57. Fry SC, Miller JG, and Dumville JC. Possible functions of copper ions in cell wall loosening. Plant Nutr. 100-101, 2001.

58. Fukui M, Yamabe N, Choi H-J, Polireddy K, Chen Q, and Zhu B. Mechanism of Ascorbate-Induced Cell Death in Human Pancreatic Cancer Cells: Role of Bcl-2, Beclin 1 and Autophagy. Planta Med. 81: 838-846, 2015.

59. Gallie DR. L-Ascorbic Acid: A Multifunctional Molecule Supporting Plant Growth and 
Development. Scientifica (Cairo). 2013: 1-24, 2013.

60. Gao M, Monian P, Pan Q, Zhang W, Xiang J, and Jiang X. Ferroptosis is an autophagic cell death process. Cell Res. 26: 1021-1032, 2016.

61. Gao Q, and Zhang L. Ultraviolet-B-induced oxidative stress and antioxidant defense system responses in ascorbate-deficient vtc1 mutants of Arabidopsis thaliana. J. Plant Physiol. 165: 138-148, 2008.

62. Gest N, Gautier H, and Stevens R. Ascorbate as seen through plant evolution: the rise of a successful molecule? J. Exp. Bot. 64: 33-53, 2013.

63. Godoy A, Ormazabal V, Moraga-Cid G, Zúñiga FA, Sotomayor P, Barra V, Vasquez O, Montecinos V, Mardones L, Guzmán C, Villagrán M, Aguayo LG, Oñate SA, Reyes AM, Cárcamo JG, Rivas $\mathrm{Cl}$, and Vera JC. Mechanistic insights and functional determinants of the transport cycle of the ascorbic acid transporter SVCT2. Activation by sodium and absolute dependence on bivalent cations. J. Biol. Chem. 282: 615-624, 2007.

64. Graumlich JF, Ludden TM, Conry-Cantilena C, Cantilena LR, Wang Y, and Levine M. Pharmacokinetic model of ascorbic acid in healthy male volunteers during depletion and repletion. Pharm. Res. 14: 1133-1139, 1997.

65. Green MA, and Fry SC. Vitamin C degradation in plant cells via enzymatic hydrolysis of 4-O-oxalyl-I-threonate. Nature 433: 83-87, 2005.

66. Guidarelli A, Cerioni L, Fiorani M, Azzolini C, and Cantoni O. Mitochondrial ascorbic acid is responsible for enhanced susceptibility of U937 cells to the toxic effects of peroxynitrite. BioFactors 40: 236-246, 2014.

67. Hallin El, Hasan M, Guo K, and Åkerlund H-E. Molecular studies on structural changes and oligomerisation of violaxanthin de-epoxidase associated with the $\mathrm{pH}$-dependent activation. Photosynth. Res. 129: 29-41, 2016.

68. Holt NE. Carotenoid Cation Formation and the Regulation of Photosynthetic Light Harvesting. Science (80-. ). 307: 433-436, 2005. 
69. Hong S-W, Lee S-H, Moon J-H, Hwang JJ, Kim DEJ, Ko E, Kim H-S, Cho IJ, Kang J-SS, Kim DEJ, Kim J-E, Shin J-S, Jung D-J, Jeong Y-J, Cho B-J, Kim T-W, Lee JS, Kang J-SS, Hwang Y-I, Noh D-Y, Jin D-H, and Lee WJ. SVCT-2 in breast cancer acts as an indicator for Lascorbate treatment. Oncogene 32: 1508-1517, 2013.

70. Hong S-W, Jin D-H, Hahm E-S, Yim S-H, Lim J-S, Kim K-I, Yang Y, Lee S-S, Kang J-S, Lee WJ, Lee W-K, and Lee M-S. Ascorbate (vitamin C) induces cell death through the apoptosis-inducing factor in human breast cancer cells. Oncol. Rep. 18: 811-815, 2007.

71. Huang C. Increased sensitivity to salt stress in an ascorbate-deficient Arabidopsis mutant. J. Exp. Bot. 56: 3041-3049, 2005.

72. Huang S, Van Aken O, Schwarzländer M, Belt K, and Millar AH. The Roles of Mitochondrial Reactive Oxygen Species in Cellular Signaling and Stress Response in Plants. Plant Physiol. 171: 1551-1559, 2016.

73. Hulse JD, Ellis SR, and Henderson LM. Carnitine biosynthesis. beta-Hydroxylation of trimethyllysine by an alpha-ketoglutarate-dependent mitochondrial dioxygenase. J. Biol. Chem. 253: 1654-1659, 1978.

74. Ibrahim WH, Habib HM, Kamal H, St. Clair DK, and Chow CK. Mitochondrial superoxide mediates labile iron level: Evidence from Mn-SOD-transgenic mice and heterozygous knockout mice and isolated rat liver mitochondria. Free Radic. Biol. Med. 65: 143-149, 2013.

75. Inupakutika MA, Sengupta S, Devireddy AR, Azad RK, and Mittler R. The evolution of reactive oxygen species metabolism. J. Exp. Bot. 67: 5933-5943, 2016.

76. Ivanov B, Asada K, and Edwards GE. Analysis of donors of electrons to photosystem I and cyclic electron flow by redox kinetics of P700 in chloroplasts of isolated bundle sheath strands of maize. Photosynth. Res. 92: 65-74, 2007.

77. Johnson RM, Goyette G, Ravindranath Y, and Ho Y-S. Hemoglobin autoxidation and regulation of endogenous $\mathrm{H} 2 \mathrm{O} 2$ levels in erythrocytes. Free Radic. Biol. Med. 39: 
1407-1417, 2005.

78. Kang JS, Cho D, Kim Y-I, Hahm E, Yang Y, Kim D, Hur D, Park H, Bang S, Hwang Y II, and Lee WJ. I-Ascorbic acid (vitamin C) induces the apoptosis of B16 murine melanoma cells via a caspase-8?independent pathway. Cancer Immunol. Immunother. 52: 693698, 2003.

79. Kärkönen A, and Fry SC. Effect of ascorbate and its oxidation products on $\mathrm{H} 2 \mathrm{O} 2$ production in cell-suspension cultures of Picea abies and in the absence of cells. J. Exp. Bot. 57: 1633-1644, 2006.

80. Karlsson PM, Herdean A, Adolfsson L, Beebo A, Nziengui H, Irigoyen S, Ünnep R, Zsiros O, Nagy G, Garab G, Aronsson H, Versaw WK, and Spetea C. The Arabidopsis thylakoid transporter PHT4;1 influences phosphate availability for ATP synthesis and plant growth. Plant J. 84: 99-110, 2015.

81. KC S, Cárcamo JM, and Golde DW. Vitamin C enters mitochondria via facilitative glucose transporter 1 (Glut1) and confers mitochondrial protection against oxidative injury. FASEB J. 19: 1657-1667, 2005.

82. Kehrer JP. The Haber-Weiss reaction and mechanisms of toxicity. Toxicology 149: 4350, 2000.

83. Kiyota M, Numayama N, and Goto K. Circadian rhythms of the l-ascorbic acid level in Euglena and spinach. J. Photochem. Photobiol. B Biol. 84: 197-203, 2006.

84. Klingelhoeffer C, Kämmerer U, Koospal M, Mühling B, Schneider M, Kapp M, Kübler A, Germer C-T, and Otto C. Natural resistance to ascorbic acid induced oxidative stress is mainly mediated by catalase activity in human cancer cells and catalase-silencing sensitizes to oxidative stress. BMC Complement. Altern. Med. 12: 61, 2012.

85. Kuiper C, Dachs GU, Currie MJ, and Vissers MCM. Intracellular ascorbate enhances hypoxia-inducible factor (HIF)-hydroxylase activity and preferentially suppresses the HIF-1 transcriptional response. Free Radic. Biol. Med. 69: 308-317, 2014.

86. Kuiper C, and Vissers MCM. Ascorbate as a Co-Factor for Fe- and 2-Oxoglutarate 
Dependent Dioxygenases: Physiological Activity in Tumor Growth and Progression. Front. Oncol. 4: 1-6, 2014.

87. Kyrtopoulos SA, Pignatelli B, Karkanias G, Golematis B, and Esteve J. Studies in gastric carcinogenesis. $\mathrm{V}$. The effects of ascorbic acid on $\mathrm{N}$-nitroso compound formation in human gastric juice in vivo and in vitro. Carcinogenesis 12: 1371-1376, 1991.

88. Laing WA, Martínez-Sánchez M, Wright MA, Bulley SM, Brewster D, Dare AP, Rassam M, Wang D, Storey R, Macknight RC, and Hellens RP. An Upstream Open Reading Frame Is Essential for Feedback Regulation of Ascorbate Biosynthesis in Arabidopsis. Plant Cell 27: 772-786, 2015.

89. Lane DJR, and Richardson DR. The active role of vitamin C in mammalian iron metabolism: much more than just enhanced iron absorption! Free Radic. Biol. Med. 75: 69-83, 2014.

90. Lee YC, Huang HY, Chang CJ, Cheng CH, and Chen YT. Mitochondrial GLUT10 facilitates dehydroascorbic acid import and protects cells against oxidative stress: Mechanistic insight into arterial tortuosity syndrome. Hum. Mol. Genet. 19: 3721-3733, 2010.

91. Letelier ME, Sánchez-Jofré S, Peredo-Silva L, Cortés-Troncoso J, and Aracena-Parks P. Mechanisms underlying iron and copper ions toxicity in biological systems: Prooxidant activity and protein-binding effects. Chem. Biol. Interact. 188: 220-227, 2010.

92. Levine M, Conry-Cantilena C, Wang Y, Welch RW, Washko PW, Dhariwal KR, Park JB, Lazarev A, Graumlich JF, King J, and Cantilena LR. Vitamin C pharmacokinetics in healthy volunteers: evidence for a recommended dietary allowance. Proc. Natl. Acad. Sci. U. S. A. 93: 3704-3709, 1996.

93. Li X, Cobb CE, Hill KE, Burk RF, and May JM. Mitochondrial uptake and recycling of ascorbic acid. Arch. Biochem. Biophys. 387: 143-153, 2001.

94. Li Z, Peers G, Dent RM, Bai Y, Yang SY, Apel W, Leonelli L, and Niyogi KK. Evolution of an atypical de-epoxidase for photoprotection in the green lineage. Nat. plants 2: 16140, 2016. 
95. Lin S-Y, Lai W-W, Chou C-C, Kuo H-M, Li T-M, Chung J-G, and Yang J-H. Sodium ascorbate inhibits growth via the induction of cell cycle arrest and apoptosis in human malignant melanoma A375.S2 cells. Melanoma Res. 16: 509-519, 2006.

96. Lisko KA, Aboobucker SI, Torres R, and Lorence A. Engineering Elevated Vitamin C in Plants to Improve their Nutritional Content, Growth, and Tolerance to Abiotic Stress. Phytochem. - Biosynthesis, Funct. Appl. 109-128, 2014.

97. Loenarz C, and Schofield CJ. Physiological and biochemical aspects of hydroxylations and demethylations catalyzed by human 2-oxoglutarate oxygenases. Trends Biochem. Sci. 36: 7-18, 2011.

98. Loiacono FV, and De Tullio MC. Why We Should Stop Inferring Simple Correlations Between Antioxidants and Plant Stress Resistance: Towards the Antioxidomic Era. Omi. A J. Integr. Biol. 16: 160-167, 2012.

99. López-Carbonell M, Munné-Bosch S, and Alegre L. The ascorbate-deficient vtc-1 Arabidopsis mutant shows altered ABA accumulation in leaves and chloroplasts. J. Plant Growth Regul. 25: 137-144, 2006.

100. Ma Y, Chapman J, Levine M, Polireddy K, Drisko J, and Chen Q. High-dose parenteral ascorbate enhanced chemosensitivity of ovarian cancer and reduced toxicity of chemotherapy. Sci. Transl. Med. 6: 222ra18, 2014.

101. MacDonald L, Thumser AE, and Sharp P. Decreased expression of the vitamin C transporter SVCT1 by ascorbic acid in a human intestinal epithelial cell line. Br. J. Nutr. 87: 97-100, 2002.

102. Mackenzie B, Illing AC, and Hediger M a. Transport model of the human Na+-coupled L-ascorbic acid (vitamin C) transporter SVCT1. AJP Cell Physiol. 294: C451-C459, 2007.

103. Malo C, and Wilson JX. Glucose modulates vitamin C transport in adult human small intestinal brush border membrane vesicles. J. Nutr. 130: 63-69, 2000.

104. Mandl J, Szarka A, and Bánhegyi G. Vitamin C: update on physiology and pharmacology. Br. J. Pharmacol. 157: 1097-1110, 2009. 
105. Mano J, Hideg É, and Asada K. Ascorbate in thylakoid lumen functions as an alternative electron donor to photosystem II and photosystem I. Arch. Biochem. Biophys. 429: 71-80, 2004.

106. Mardones $L$, Ormazabal $V$, Romo X, Jaña $C$, Binder $P$, Peña $E$, Vergara $M$, and Zúñiga FA. The glucose transporter-2 (GLUT2) is a low affinity dehydroascorbic acid transporter. Biochem. Biophys. Res. Commun. 410: 7-12, 2011.

107. Maruta T, Sawa Y, Shigeoka S, and Ishikawa T. Diversity and Evolution of Ascorbate Peroxidase Functions in Chloroplasts: More Than Just a Classical Antioxidant Enzyme? Plant Cell Physiol. 57: pcv203, 2016.

108. Maulén NP, Henríquez EA, Kempe S, Cárcamo JG, Schmid-Kotsas A, Bachem M, Grünert A, Bustamante ME, Nualart F, and Vera JC. Up-regulation and polarized expression of the sodium-ascorbic acid transporter SVCT1 in post-confluent differentiated CaCo-2 cells. J. Biol. Chem. 278: 9035-9041, 2003.

109. Maurino VG, Grube E, Zielinski J, Schild A, Fischer K, and Flugge U-I. Identification and Expression Analysis of Twelve Members of the Nucleobase-Ascorbate Transporter (NAT) Gene Family in Arabidopsis thaliana. Plant Cell Physiol. 47: 1381-1393, 2006.

110. McGarvey DJ, and Christoffersen RE. Characterization and kinetic parameters of ethylene-forming enzyme from avocado fruit. J. Biol. Chem. 267: 5964-5967, 1992.

111. Michels AJ, and Hagen TM. Hepatocyte nuclear factor 1 is essential for transcription of sodium-dependent vitamin C transporter protein 1. AJP Cell Physiol. 297: C1220C1227, 2009.

112. Michels AJ, Hagen TM, and Frei B. Human genetic variation influences vitamin C homeostasis by altering vitamin C transport and antioxidant enzyme function. Annu. Rev. Nutr. 33: 45-70, 2013.

113. Millar a H. Control of Ascorbate Synthesis by Respiration and Its Implications for Stress Responses. PLANT Physiol. 133: 443-447, 2003.

114. Mittler R. ROS Are Good. Trends Plant Sci. 22: 11-19, 2017. 
115. Miyaji T, Kuromori T, Takeuchi Y, Yamaji N, Yokosho K, Shimazawa A, Sugimoto E, Omote H, Ma JF, Shinozaki K, and Moriyama Y. AtPHT4;4 is a chloroplast-localized ascorbate transporter in Arabidopsis. Nat. Commun. 6: 5928, 2015.

116. Muller-Moule P. Zeaxanthin Deficiency Enhances the High Light Sensitivity of an Ascorbate-Deficient Mutant of Arabidopsis. PLANT Physiol. 133: 748-760, 2003.

117. Muller K, Linkies A, Vreeburg RAM, Fry SC, Krieger-Liszkay A, and Leubner-Metzger G. In Vivo Cell Wall Loosening by Hydroxyl Radicals during Cress Seed Germination and Elongation Growth. PLANT Physiol. 150: 1855-1865, 2009.

118. Munné-Bosch S. The role of -tocopherol in plant stress tolerance. J. Plant Physiol. 162: 743-748, 2005.

119. Muñoz-Montesino C, Roa FJ, Peña E, González M, Sotomayor K, Inostroza E, Muñoz CA, González I, Maldonado M, Soliz C, Reyes AM, Vera JC, and Rivas Cl. Mitochondrial ascorbic acid transport is mediated by a low-affinity form of the sodium-coupled ascorbic acid transporter-2. Free Radic. Biol. Med. 70: 241-254, 2014.

120. Nagy V, Vidal-Meireles A, Tengölics R, Rákhely G, Garab G, Kovács L, and Tóth SZ. Ascorbate accumulation during sulphur deprivation and its effects on photosystem II activity and $\mathrm{H} 2$ production of the green alga Chlamydomonas reinhardtii. Plant. Cell Environ. 39: 1460-1472, 2016.

121. Nishikimi M, and Yagi K. Molecular basis for the deficiency in humans of gulonolactone oxidase, a key enzyme for ascorbic acid biosynthesis. Am. J. Clin. Nutr. 54: 1203S-1208S, 1991.

122. Niyogi KK. Arabidopsis Mutants Define a Central Role for the Xanthophyll Cycle in the Regulation of Photosynthetic Energy Conversion. Plant Cell 10: 1121-1134, 1998.

123. Padayatty SJ, Riordan HD, Hewitt SM, Katz A, Hoffer L, and Levine M. Intravenously administered vitamin C as cancer therapy: Three cases. Cmaj 174: 937-942, 2006.

124. Padayatty SJ, Sun H, Wang Y, Riordan HD, Hewitt SM, Katz A, Wesley RA, and Levine M. Vitamin C pharmacokinetics: implications for oral and intravenous use. Ann. 
Intern. Med. 140: 533-537, 2004.

125. Page EL, Chan DA, Giaccia AJ, Levine M, and Richard DE. Hypoxia-inducible Factor-1 Stabilization in Nonhypoxic Conditions: Role of Oxidation and Intracellular Ascorbate Depletion. Mol. Biol. Cell 19: 86-94, 2008.

126. Page $M$, Sultana $N$, Paszkiewicz $K$, Florance $H$, and Smirnoff $N$. The influence of ascorbate on anthocyanin accumulation during high light acclimation in Arabidopsis thaliana: further evidence for redox control of anthocyanin synthesis. Plant. Cell Environ. 35: 388-404, 2012.

127. Parrow NL, Leshin JA, and Levine M. Parenteral ascorbate as a cancer therapeutic: a reassessment based on pharmacokinetics. Antioxid. Redox Signal. 19: 2141-2156, 2013.

128. Pastori GM. Leaf Vitamin C Contents Modulate Plant Defense Transcripts and Regulate Genes That Control Development through Hormone Signaling. Plant Cell 15: 939-951, 2003.

129. Qian HF, Peng XF, Han X, Ren J, Zhan KY, and Zhu M. The stress factor, exogenous ascorbic acid, affects plant growth and the antioxidant system in Arabidopsis thaliana. Russ. J. Plant Physiol. 61: 467-475, 2014.

130. Qiao H, and May JM. Regulation of the human ascorbate transporter SVCT2 exon $1 \mathrm{~b}$ gene by zinc-finger transcription factors. Free Radic. Biol. Med. 50: 1196-1209, 2011.

131. Reidling JC, and Rubin SA. Promoter analysis of the human ascorbic acid transporters SVCT1 and 2: Mechanisms of adaptive regulation in liver epithelial cells. J. Nutr. Biochem. 22: 344-350, 2011.

132. Rose RC. Transport of ascorbic acid and other water-soluble vitamins. Biochim. Biophys. Acta - Rev. Biomembr. 947: 335-366, 1988.

133. Rumsey SC, Kwon O, Xu GW, Burant CF, Simpson I, and Levine M. Glucose transporter isoforms GLUT1 and GLUT3 transport dehydroascorbic acid. J. Biol. Chem. 272: 18982-18989, 1997. 
134. Rumsey SC, Daruwala R, Al-Hasani H, Zarnowski MJ, Simpson I a, and Levine M. Dehydroascorbic acid transport by GLUT4 in Xenopus oocytes and isolated rat adipocytes. J. Biol. Chem. 275: 28246-28253, 2000.

135. Savini I, Rossi A, Pierro C, Avigliano L, and Catani M V. SVCT1 and SVCT2: Key proteins for vitamin C uptake. Amino Acids 34: 347-355, 2008.

136. Savini I, Catani MV, Arnone R, Rossi A, Frega G, Del Principe D, and Avigliano L. Translational control of the ascorbic acid transporter SVCT2 in human platelets. Free Radic. Biol. Med. 42: 608-616, 2007.

137. Savini I, Rossi A, Catani MV, Ceci R, and Avigliano L. Redox regulation of vitamin C transporter SVCT2 in C2C12 myotubes. Biochem. Biophys. Res. Commun. 361: 385390, 2007.

138. Schmidt S, Joost H-G, and Schürmann A. GLUT8, the enigmatic intracellular hexose transporter. Am. J. Physiol. Endocrinol. Metab. 296: E614-E618, 2009.

139. Schoenfeld JD, Sibenaller ZA, Mapuskar KA, Buatti JM, Spitz DR, and Allen BG. O2 and H2O2 Mediated Disruption of Fe Metabolism Causes the Differential Susceptibility of NSCLC and GBM Cancer Cells to Pharmacological Ascorbate. Cancer Cell 31: 1-14, 2017.

140. Schopfer P, Liszkay A, Bechtold M, Frahry G, and Wagner A. Evidence that hydroxyl radicals mediate auxin-induced extension growth. Planta 214: 821-828, 2002.

141. Schraufstatter IU, Hinshaw DB, Hyslop PA, Spragg RG, and Cochrane CG. Oxidant injury of cells. DNA strand-breaks activate polyadenosine diphosphate-ribose polymerase and lead to depletion of nicotinamide adenine dinucleotide. J. Clin. Invest. 77: 1312-1320, 1986.

142. Segade F. Glucose transporter 10 and arterial tortuosity syndrome: The vitamin C connection. FEBS Lett. 584: 2990-2994, 2010.

143. Selig RA, Madafiglio J, Haber M, Norris MD, White L, and Stewart BW. Ferritin production and desferrioxamine cytotoxicity in human neuroblastoma cell lines. 
Anticancer Res. 13: 721-725, 1993.

144. Shi YC, Fu YP, and Liu WQ. NADPH oxidase in plasma membrane is involved in stomatal closure induced by dehydroascorbate. Plant Physiol. Biochem. 51: 26-30, 2012.

145. Smith JJ, Ververidis P, and John P. Characterization of the ethylene-forming enzyme partially purified from melon. Phytochemistry 31: 1485-1494, 1992.

146. Sotiriou S, Gispert S, Cheng J, Wang Y, Chen A, Hoogstraten-Miller S, Miller GF, Kwon O, Levine M, Guttentag SH, and Nussbaum RL. Ascorbic-acid transporter Slc23a1 is essential for vitamin C transport into the brain and for perinatal survival. Nat. Med. 8: 514-517, 2002.

147. Subramanian VS, Marchant JS, Boulware MJ, and Said HM. A C-terminal region dictates the apical plasma membrane targeting of the human sodium-dependent vitamin C transporter-1 in polarized epithelia. J. Biol. Chem. 279: 27719-27728, 2004.

148. Subramanian VS, Srinivasan P, Wildman AJ, Marchant JS, and Said HM. Molecular mechanism(s) involved in differential expression of vitamin C transporters along the intestinal tract. Am. J. Physiol. - Gastrointest. Liver Physiol. 312: G340-G347, 2017.

149. Szarka A, and Balogh T. In silico aided thoughts on mitochondrial vitamin C transport. J. Theor. Biol. 365: 181-189, 2015.

150. Szarka A, Bánhegyi G, and Asard H. The Inter-Relationship of Ascorbate Transport, Metabolism and Mitochondrial, Plastidic Respiration. Antioxid. Redox Signal. 19: 1036-1044, 2013.

151. Szarka A, Horemans N, Bánhegyi G, and Asard H. Facilitated glucose and dehydroascorbate transport in plant mitochondria. Arch. Biochem. Biophys. 428: 7380, 2004.

152. Szarka A, and Lőrincz T. The role of ascorbate in protein folding. Protoplasma 251: 489-497, 2014. 
153. Szarka A, Stadler K, Jenei V, Margittai É, Csala M, Jakus J, Mandl J, and Bánhegyi G. Ascorbyl free radical and dehydroascorbate formation in rat liver endoplasmic reticulum. J. Bioenerg. Biomembr. 34: 317-323, 2002.

154. Tamura $\mathrm{N}$, Inoue $\mathrm{H}$, and Inoue $\mathrm{Y}$. Inactivation of the Water-Oxidizing Complex by Exogenous Reductants in PS II Membranes Depleted of Extrinsic Proteins. Plant Cell Physiol. 31: 469-477, 1990.

155. Todhunter EN, McMillan T, and Ehmke DA. Utilization of dehydroascorbic acid by human subjects. J. Nutr. 42: 297-308, 1950.

156. Torti S V, and Torti FM. Iron and cancer: more ore to be mined. Nat. Rev. Cancer 13: 342-355, 2013.

157. Toth SZ, Nagy V, Puthur JT, Kovacs L, and Garab G. The Physiological Role of Ascorbate as Photosystem II Electron Donor: Protection against Photoinactivation in HeatStressed Leaves. PLANT Physiol. 156: 382-392, 2011.

158. Toth SZ, Puthur JT, Nagy V, and Garab G. Experimental Evidence for AscorbateDependent Electron Transport in Leaves with Inactive Oxygen-Evolving Complexes. PLANT Physiol. 149: 1568-1578, 2009.

159. Toyokuni S, Ito F, Yamashita K, Okazaki Y, and Akatsuka S. Iron and thiol redox signaling in cancer: An exquisite balance to escape ferroptosis. Free Radic. Biol. Med. 108: 610-626, 2017.

160. Truffault V, Fry SC, Stevens RG, and Gautier H. Ascorbate degradation in tomato leads to accumulation of oxalate, threonate and oxalyl threonate. Plant J. 89: 996-1008, 2017.

161. Tsukaguchi H, Tokui T, Mackenzie B, Berger U V, Chen XZ, Wang Y, Brubaker RF, and Hediger MA. A family of mammalian Na+-dependent L-ascorbic acid transporters. Nature 399: 70-75, 1999.

162. Ullah MF, Khan HY, Zubair H, Shamim U, and Hadi SM. The antioxidant ascorbic acid mobilizes nuclear copper leading to a prooxidant breakage of cellular DNA: 
implications for chemotherapeutic action against cancer. Cancer Chemother.

Pharmacol. 67: 103-110, 2011.

163. Upham BL, and Jahnke LS. Photooxidative reactions in chloroplast thylakoids.

Evidence for a Fenton-type reaction promoted by superoxide or ascorbate. Photosynth. Res. 8: 235-247, 1986.

164. Urzica El, Adler LN, Page MD, Linster CL, Arbing MA, Casero D, Pellegrini M, Merchant SS, and Clarke SG. Impact of Oxidative Stress on Ascorbate Biosynthesis in Chlamydomonas via Regulation of the VTC2 Gene Encoding a GDP-I-galactose Phosphorylase. J. Biol. Chem. 287: 14234-14245, 2012.

165. Varma S, Sobey K, Campbell CE, and Kuo SM. Hierarchal contribution of N- and Cterminal sequences to the differential localization of homologous sodium-dependent vitamin C transporters, SVCT1 and SVCT2, in epithelial cells. Biochemistry 48: 29692980, 2009.

166. Vera JC, Rivas Cl, Fischbarg J, and Golde DW. Mammalian facilitative hexose transporters mediate the transport of dehydroascorbic acid. Nature 364: 79-82, 1993.

167. Verrax J, and Calderon PB. Pharmacologic concentrations of ascorbate are achieved by parenteral administration and exhibit antitumoral effects. Free Radic. Biol. Med. 47: 32-40, 2009.

168. Vidal-Meireles A, Neupert J, Zsigmond L, Rosado-Souza L, Kovács L, Nagy V, Galambos A, Fernie AR, Bock R, and Tóth SZ. Regulation of ascorbate biosynthesis in green algae has evolved to enable rapid stress-induced response via the VTC2 gene encoding GDP- I -galactose phosphorylase. New Phytol. 214: 668-681, 2017.

169. Wang C, Lv H, Yang W, Li T, Fang T, Lv G, Han Q, Dong L, Jiang T, Jiang B, Yang G, and Wang H. SVCT-2 determines the sensitivity to ascorbate-induced cell death in cholangiocarcinoma cell lines and patient derived xenografts. Cancer Lett. 398: 1-11, 2017.

170. Wang H, Dutta B, Huang W, Devoe LD, Leibach FH, Ganapathy V, and Prasad PD. 
Human Na+-dependent vitamin C transporter 1 (hSVCT1): primary structure, functional characteristics and evidence for a non-functional splice variant. Science (80-. ). 1461: 1-9, 1999.

171. Wang Y, Mackenzie B, Tsukaguchi H, Weremowicz S, Morton CC, and Hediger M a. Human vitamin C (L-ascorbic acid) transporter SVCT1. Biochem. Biophys. Res. Commun. 267: 488-494, 2000.

172. Wang Z, Xiao Y, Chen W, Tang K, and Zhang L. Increased Vitamin C Content Accompanied by an Enhanced Recycling Pathway Confers Oxidative Stress Tolerance in Arabidopsis. J. Integr. Plant Biol. 52: 400-409, 2010.

173. Wheeler G, Ishikawa T, Pornsaksit V, and Smirnoff N. Evolution of alternative biosynthetic pathways for vitamin $\mathrm{C}$ following plastid acquisition in photosynthetic eukaryotes. Elife 4: 2015.

174. Wojtaszek P, Smith CG, and Bolwell GP. Ultrastructural localisation and further biochemical characterisation of prolyl 4-hydroxylase from Phaseolus vulgaris: comparative analysis. Int. J. Biochem. Cell Biol. 31: 463-477, 1999.

175. Wolucka BA, and Van Montagu M. GDP-Mannose 3',5'-Epimerase Forms GDP-Lgulose, a Putative Intermediate for the de Novo Biosynthesis of Vitamin C in Plants. J. Biol. Chem. 278: 47483-47490, 2003.

176. Wolucka BA, and Van Montagu M. The VTC2 cycle and the de novo biosynthesis pathways for vitamin C in plants: An opinion. Phytochemistry 68: 2602-2613, 2007. 


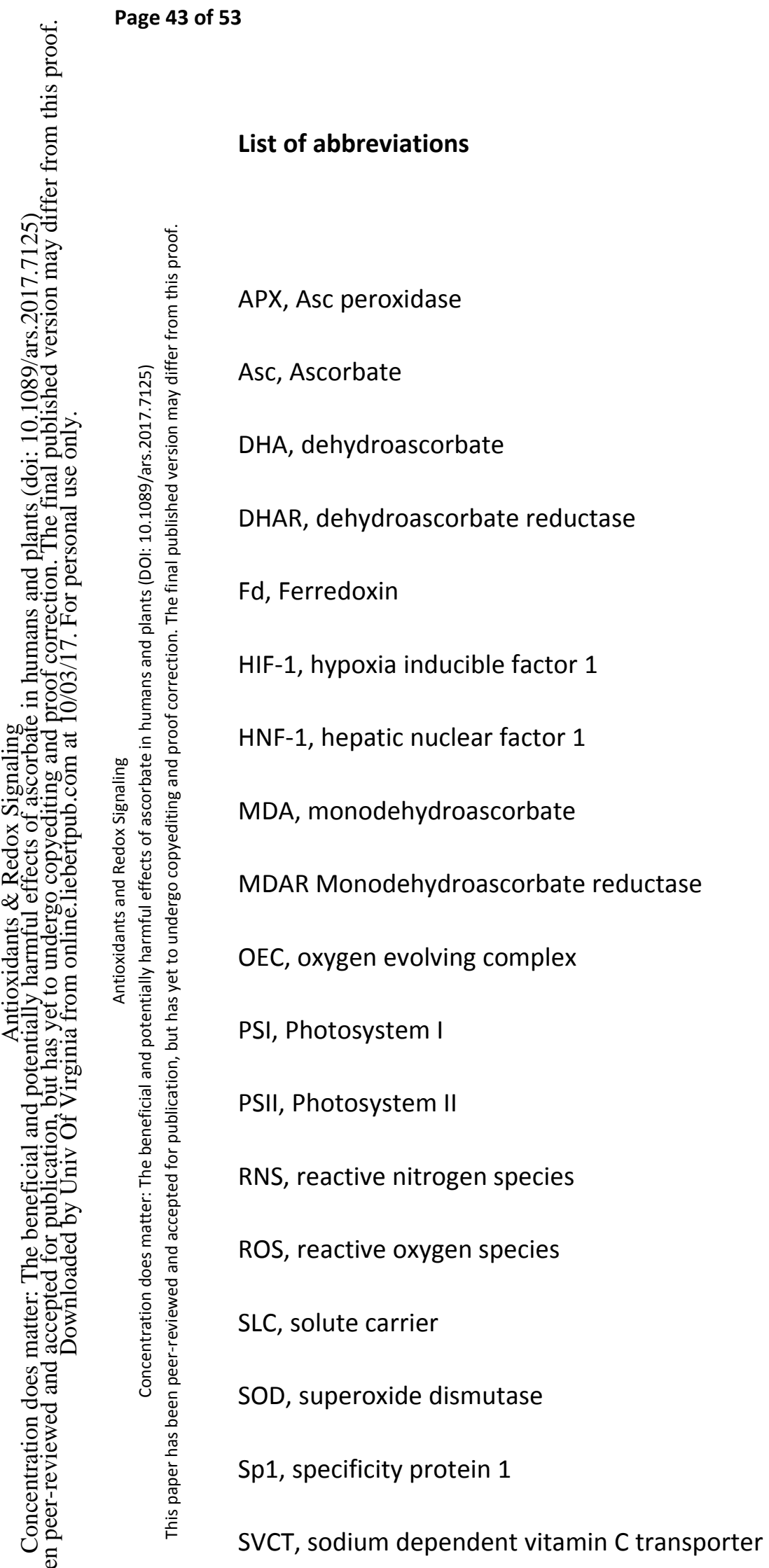


Page 44 of 53

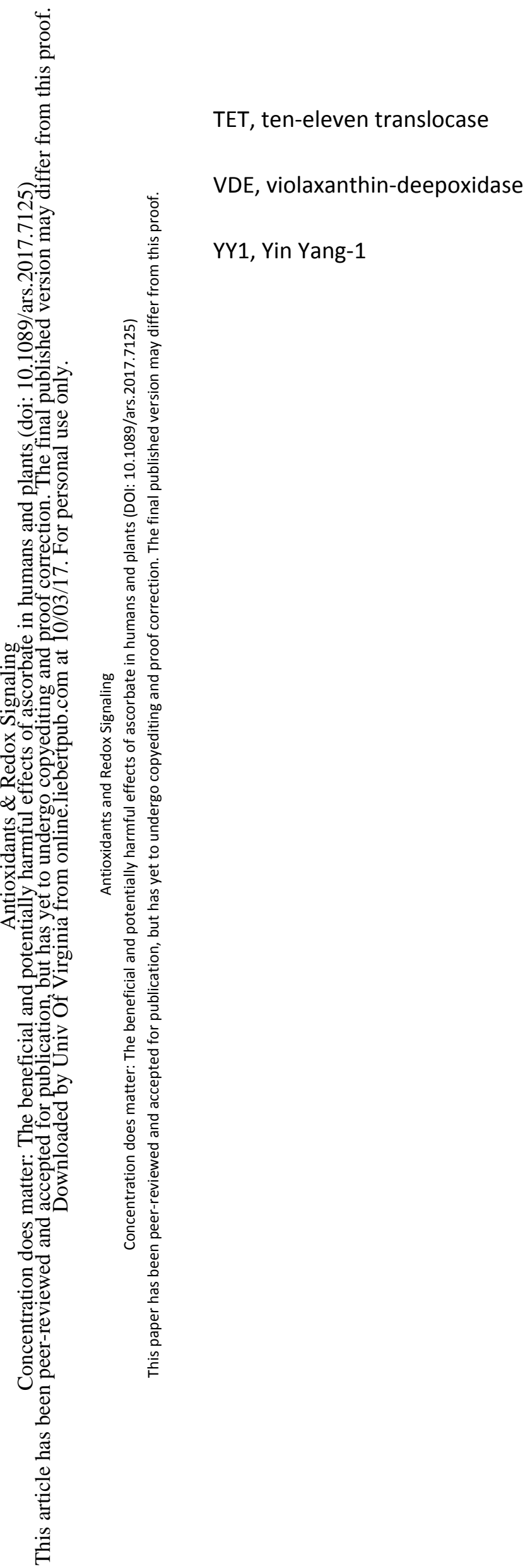




\section{Figure legends}

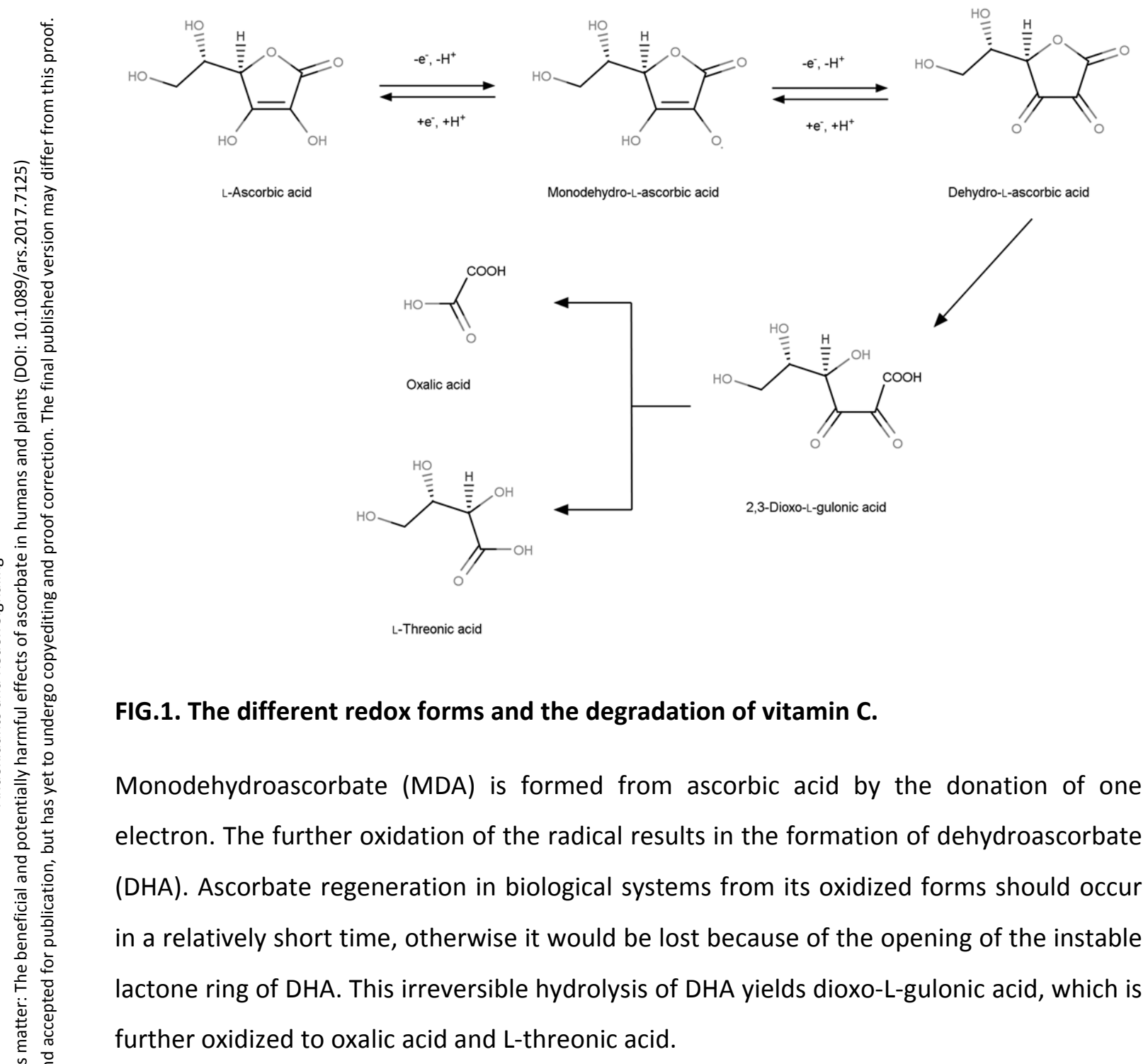




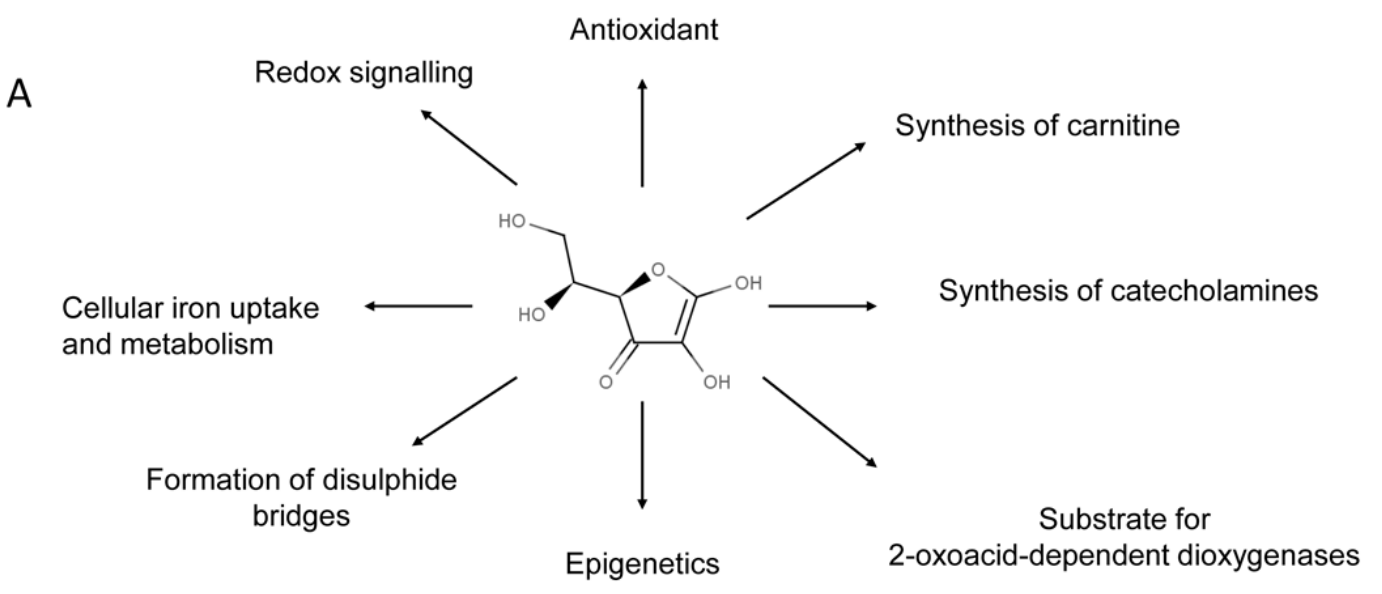

B

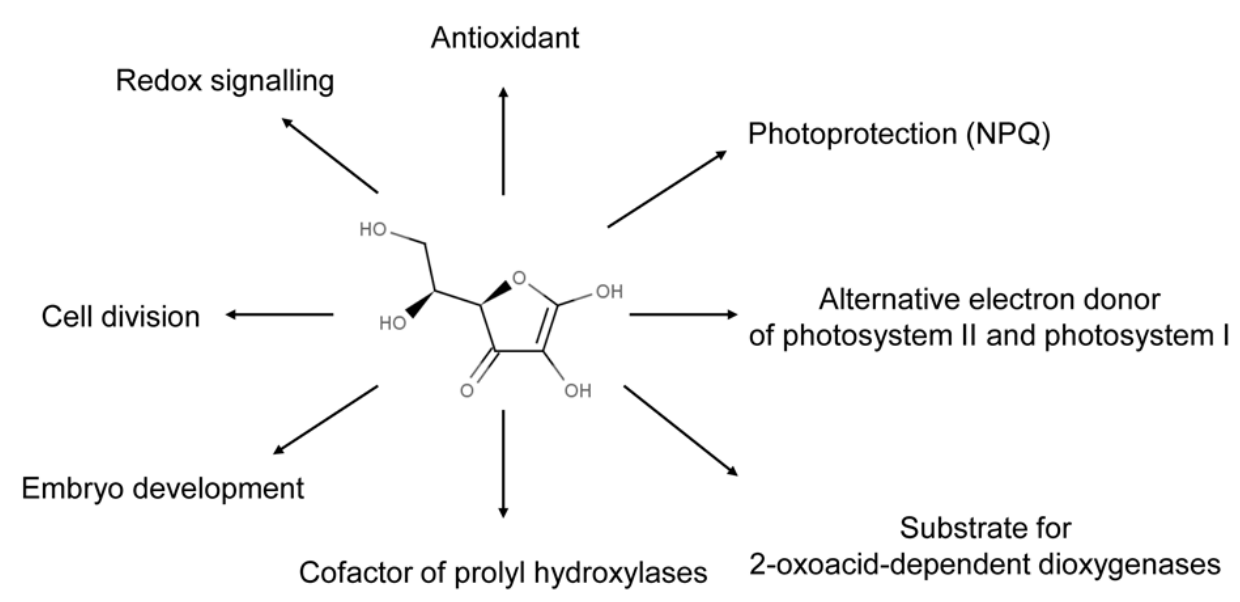

\section{FIG.2. Roles of ascorbate in humans (A) and plants (B).}

The figure depicts the presently known functions of vitamin C in plants and humans, however it is worth to note that our knowledge on its biological functions is constantly broaden. All the known functions are associated with its excellent electron donor feature. 


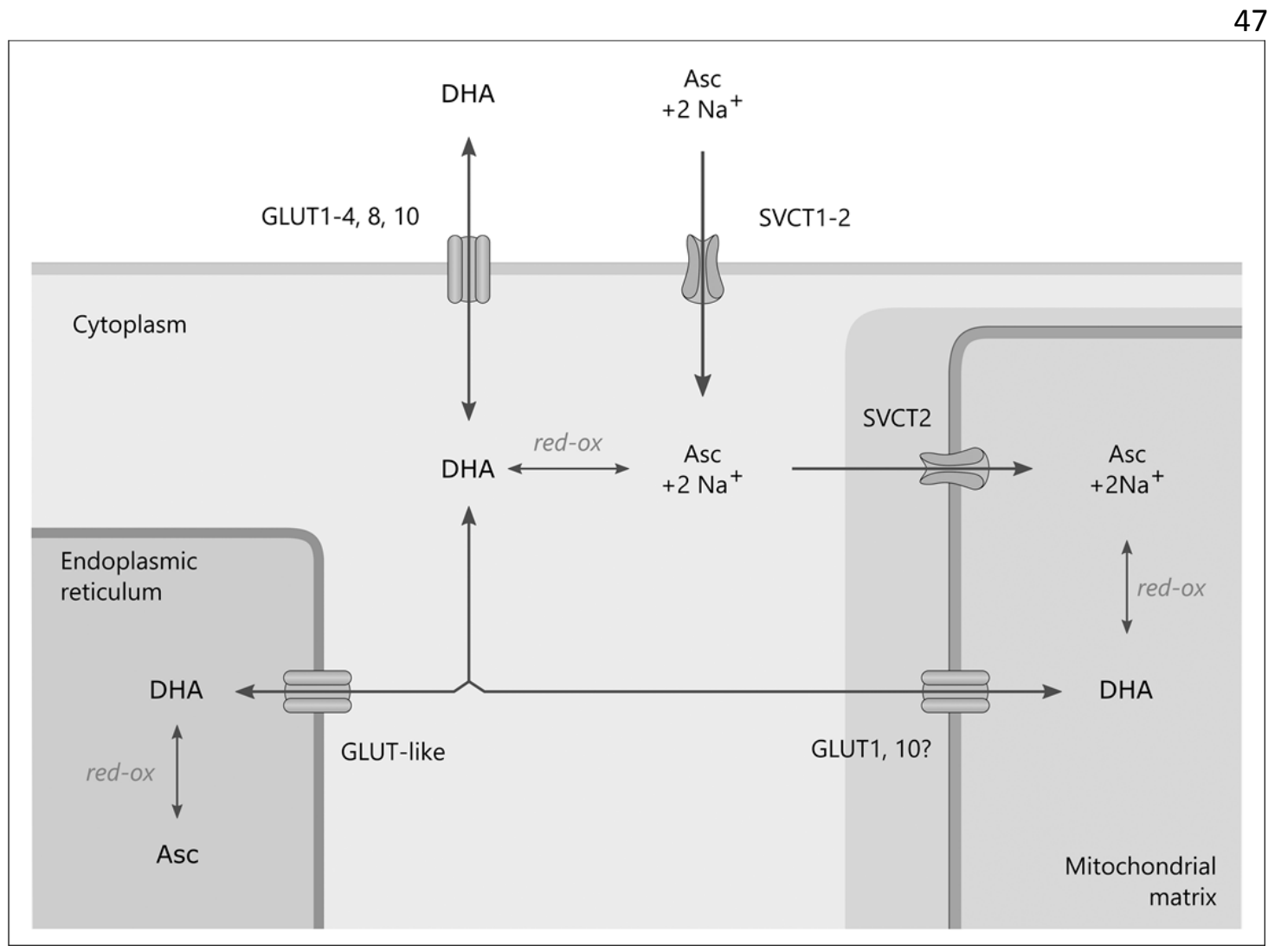

FIG. 3. Transport of vitamin C across the plasma and intracellular membranes. Ascorbate (Asc) is transported by SVCT1 and SVCT2 transporters. Both transporters cotransport $\mathrm{Na}^{+}$ and Asc with a 2:1 stoichiometry along the electrochemical $\mathrm{Na}^{+}$gradient. The facilitated diffusion of DHA is mediated by GLUT1, 2, 3 and 4 transporters from class I and by GLUT8 and 10 transporters from class III glucose transporters. Mitochondrial vitamin C transport is the best characterized among the subcellular transports. Recently the mitochondrial presence of SVCT2 was strengthened by experimental and in silico tools. GLUT1 has been described as a mitochondrial DHA transporter. No other transporter protein has been identified at the subcellular level, only a functional study found the preferential uptake of DHA in mammalian microsomal vesicles. 


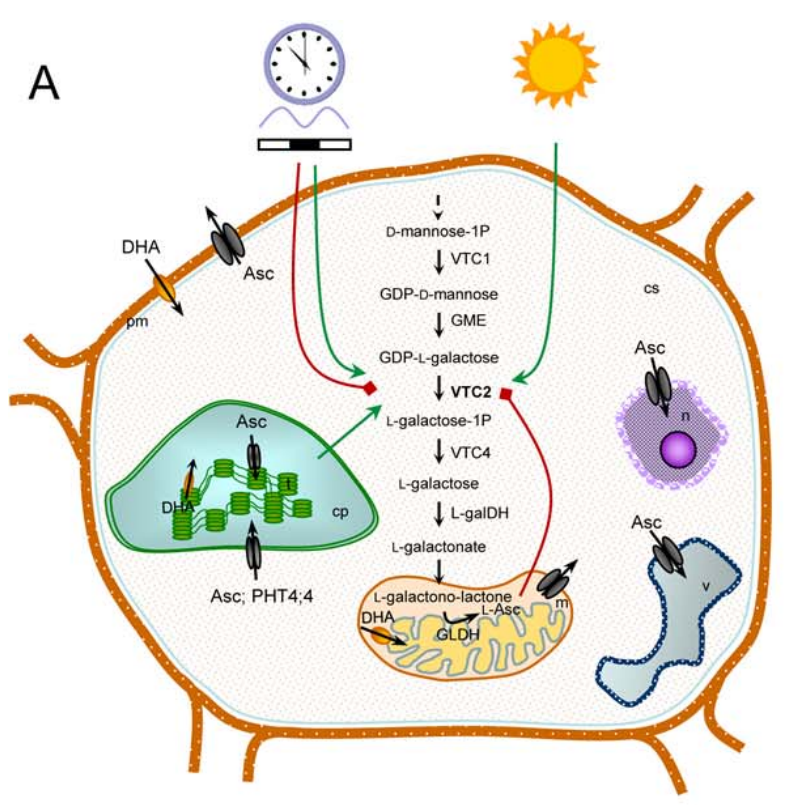

B

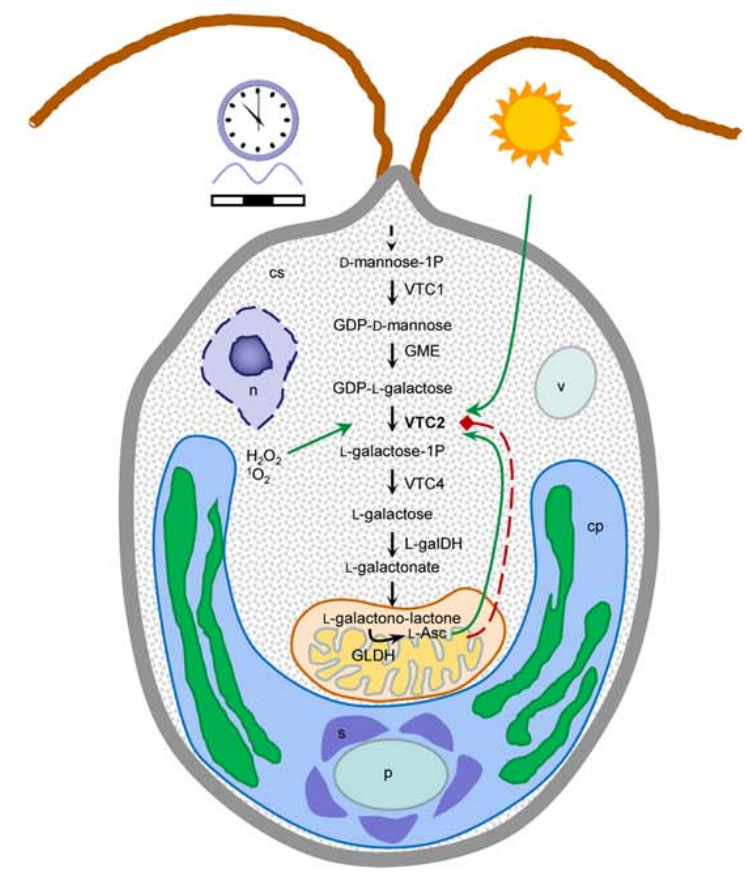

FIG. 4. Ascorbate (Asc) biosynthesis and its regulation in seed plants (A) and green algae (B), and identified and putative Asc transporters in seed plants (A). Asc is synthesized mostly via the Smirnoff-Wheeler pathway both in seed plants and green algae. Enzymes of the Smirnoff-Wheeler pathway include VTC1, GDP-mannose pyrophosphorylase; GME, GDP-mannose-3',5'-epimerase; VTC2, GDP-L-galactose phosphorylase; VTC4, L-galactose- 
1-phosphate phosphatase; L-galDH, L-galactose dehydrogenase; GLDH, L-GalL dehydrogenase.

Most of the steps occur in the cytosol, except for the final step, taking place in the mitochondrium. The VTC2 gene, encoding GDP-L-galactose phosphorylase, plays a major role in the regulation of Asc biosynthesis. In higher plants, its expression is induced by light, regulated by photosynthetic reactions via poorly understood mechanisms and by the circadian clock. The expression of VTC2 and the translation of the enzyme are both feedback-inhibited by Asc. In green algae, light and reactive oxygen species induce the expression of VTC2 and Asc has a stimulatory effect on its expression in the low, physiological concentration range; however, a feedback inhibition in the $\mathrm{mM}$ range is also likely to take place. The Asc content does not depend on the circadian rhythm in green algae.

In seed plants, characterized Asc transporters include a dehydroascorbate (DHA) transporter in the plasma membrane that is distinct of glucose carriers; a DHA transporter, probably similar to glucose transporters is located in the mitochondrium; and AtPHT4;4 was identified as a chloroplast-localized Asc transporter. Putative Asc and DHA transporters include Asc transporters responsible for the export of Asc out of the mitochondrium, into the thylakoid lumen and through the plasma membrane, transporters for ensuring the uptake of Asc into the vacuole and possibly into the nucleus (alternatively, ascorbate diffuses through the nuclear pores). DHA also has to be transported out of the thylakoid lumen for regeneration. $c s$, cytosol; $c p$, chloroplast; m, mitochondrium; $n$, nucleus; $p$, pyrenoid; pm, plasma membrane; s, strarch granules; $t$, thylakoid membrane; $v$, vacuole. 


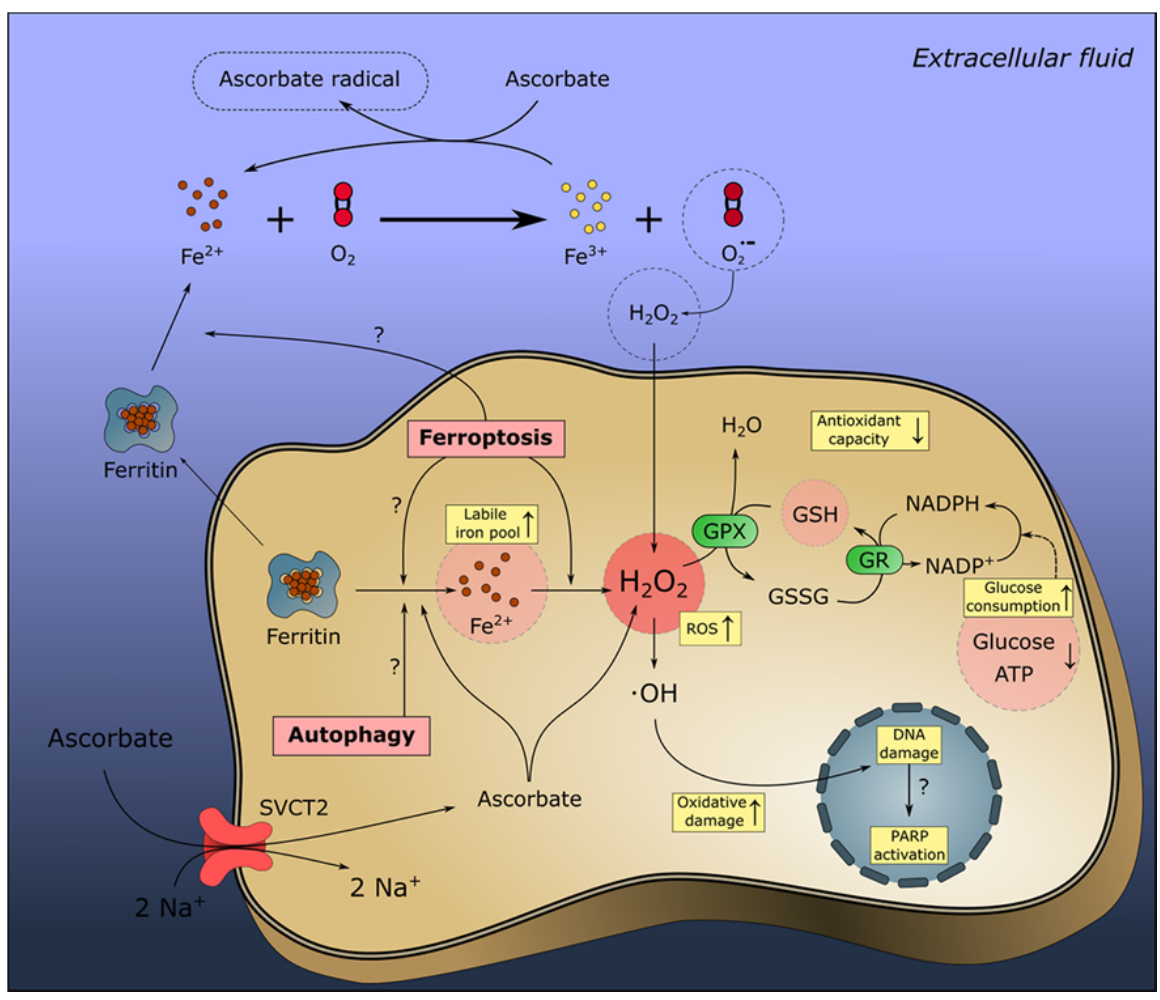

FIG. 5. The generation of ROS by high dose ascorbate (Asc) and their potential role in cell death mechanisms.

At high concentrations, ascorbate contributes to $\mathrm{H}_{2} \mathrm{O}_{2}$ generation, in which intracellular metals play an important role. The high dose Asc induce cytotoxicity associated with increased ferritin release. The elevated ferritin production and secretion can serve as a continuous iron source for ascorbate-mediated $\mathrm{H}_{2} \mathrm{O}_{2}$ production. ROS and Asc can disrupt cellular iron metabolism that leads to an increased labile iron pool. Cancer cells show significant dose-dependent Asc-induced elevation in cellular labile iron pool that cannot be observed in normal human primary cells. The high concentration of $\mathrm{H}_{2} \mathrm{O}_{2}$ in the presence of high labile iron facilitates the occurrence of Fenton reaction that generate the highly toxic hydroxyl radical. The scavenging of $\mathrm{H}_{2} \mathrm{O}_{2}$ by glutathione peroxidases (GPX) or by catalase can prevent the elevation of labile iron pool and cytotoxicity of high dose Asc. Ascorbate is not toxic for normal cells because of their lower labile iron levels and basal and Asc-mediated $\mathrm{H}_{2} \mathrm{O}_{2}$, which is metabolized quickly before it can take part in pro-oxidant reactions. 

apoptotic. However, recent studies proposed autophagy as a potential high dose Ascinduced cell death mechanism. The autophagy pathway was detected by the processing of LC3 to LC3-II and the redistribution of LC3-II to the surface of autophagosomes. SVCT-2 sensitizes cancer cells to autophagic damage by increasing the ascorbate concentration and intracellular ROS production. The knockdown of SVCT-2 dramatically alleviated DNA damage, ATP depletion, and inhibition of mTOR pathway induced by ascorbate. These observations suggest that the intracellular ROS formation beside the extracellular one may also contribute to Asc-mediated cytotoxicity. 
A

Photosystem II
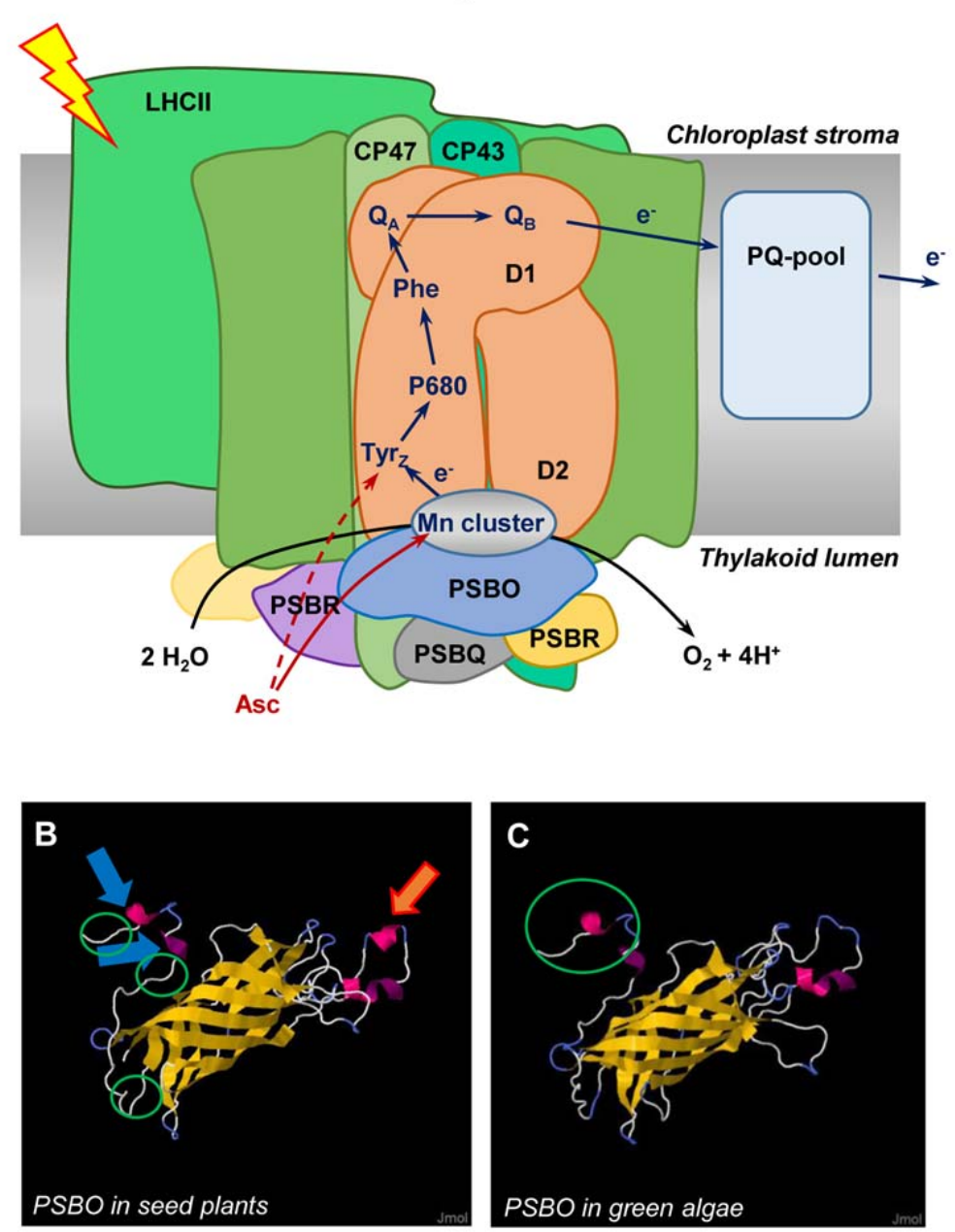

FIG. 6. Schematic presentation of photosystem II (PSII) and the effect of ascorbate (Asc) on electron transport.

(A) Solar energy is captured by the light-harvesting complexes (LHCII) of PSII. Electrons extracted from water by the oxygen-evolving complex (OEC) of PSII are transferred to the PSII reaction center, the plastoquinone (PQ)-pool, several photosynthetic complexes and finally to the Calvin-Benson cycle. The OEC is a vulnerable component of the photosynthetic electron transport chain. Upon heat stress, the extrinsic proteins of the OEC are released (primarily PSBO) and this is followed by the inactivation of the Mncluster. Under these conditions, Asc may provide electrons directly to $\mathrm{Tyr}_{z}{ }^{+}$, sustaining a 
limited electron transport activity (see main text). In green algae, Asc may over-reduce the Mn-cluster when present in the $\mathrm{mM}$ range (denoted with continuous red line), and then provides electrons to $\mathrm{Tyr}_{\mathrm{z}}^{+}$. In seed plants, Asc is not capable of inactivating the OEC at the $\mathrm{mM}$ concentration range, typical for the thylakoid lumen. The difference between green algae and seed plants is tentatively attributed to the differences between the PSBO protein structures of seed plants (B) and green algae (C): in seed plants, there are two disulfide bridges (denoted by blue arrows), whereas there is none in green algae; the binding sites (denoted by green circles) are spread in seed plants, whereas they are all located at the $\mathrm{N}$-terminus in green algae; the plant PSBO protein is less accessible to solvents than that of green algae; seed plant PSBO has also an extra strand (denoted by a red arrow). Model created by The PredictProtein server. 